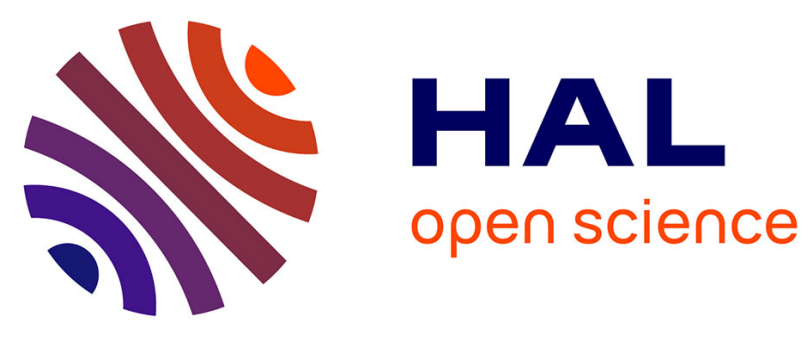

\title{
Recovery and antioxidant activity of phenolic compounds extracted from walnut press-cake using various methods and conditions
}

Maria del Pilar Garcia-Mendoza, Faber Ariel Espinosa-Pardo, Raphaëlle Savoire, Clément Etchegoyen, Christelle Harscoat-Schiavo, Pascale

\author{
Subra-Paternault
}

\section{To cite this version:}

Maria del Pilar Garcia-Mendoza, Faber Ariel Espinosa-Pardo, Raphaëlle Savoire, Clément Etchegoyen, Christelle Harscoat-Schiavo, et al.. Recovery and antioxidant activity of phenolic compounds extracted from walnut press-cake using various methods and conditions. Industrial Crops and Products, 2021, 167, pp.113546. 10.1016/j.indcrop.2021.113546 . hal-03366194

\section{HAL Id: hal-03366194 \\ https://hal.science/hal-03366194}

Submitted on 5 Oct 2021

HAL is a multi-disciplinary open access archive for the deposit and dissemination of scientific research documents, whether they are published or not. The documents may come from teaching and research institutions in France or abroad, or from public or private research centers.
L'archive ouverte pluridisciplinaire HAL, est destinée au dépôt et à la diffusion de documents scientifiques de niveau recherche, publiés ou non, émanant des établissements d'enseignement et de recherche français ou étrangers, des laboratoires publics ou privés. 


\section{Recovery and antioxidant activity of phenolic compounds extracted from walnut}

$$
\text { press-cake using various methods and conditions }
$$

Maria del Pilar Garcia-Mendoza, Faber Ariel Espinosa-Pardo, Raphaëlle Savoire*, Clément Etchegoyen, Christelle Harscoat-Schiavo, Pascale Subra-Paternault

Université Bordeaux, CNRS, Bordeaux INP, Institut CBMN UMR 5248, Allée Geoffroy SaintHilaire, 33600 Pessac, France.

\section{*Corresponding author : Dr R. Savoire, raphaelle.savoire@enscbp.fr}

\section{Abstract.}

Walnut press-cake is a residue of oil processing from which the phenolic compounds have been extracted using ethanol $60 \%$ by batch and semi-continuous operations, or by ultrasound-assisted maceration in the case of a de-oiled cake, with a particular emphasis on the variables time and solidsolvent ratio. For batch extraction, the conditions maximizing total phenolic yield (TPC) and radical scavenging activity (DPPH) were $60^{\circ} \mathrm{C}$ without the addition of phospholipids, with, however, for TPC, an extraction time of $60 \mathrm{~min}$ and a ratio of $25 \mathrm{~mL}$ of solvent per $\mathrm{g}$ of cake. Values of up to 14.8 mg GAE/gcake and $136.9 \mu \mathrm{mol}$ Trolox Equiv./gcake were obtained. The semi-continuous variant resulted in a TPC of $19.8 \mathrm{mg} \mathrm{GAE} / \mathrm{g}_{\text {cake }}$ and an overall extract containing $8 \%$ of phenolic compounds and $46 \%$ of oil. After de-oiling, the cake was subjected to ultrasound-assisted extraction. TPC and DPPH varied slightly with the conditions applied, between 10.4 and $13.3 \mathrm{mg} \mathrm{GAE} / \mathrm{g}_{\text {cake }}$ and 83 to $107 \mu \mathrm{mol}$ Trolox Equiv./g $\mathrm{g}_{\text {cake }}$ respectively, unless the solid/solvent ratio increased to 1/200 (TPC of $\left.29 \mathrm{mg} \mathrm{GAE} / \mathrm{g}_{\text {cake }}\right)$. It has been also shown that the oxidative stability of camelina oil can be increased from 24 to $72 \mathrm{~h}$ by enrichment with walnut extract. 
27 Key-words. Walnut press-cake; phenolic compounds; oil oxidative stability; batch and semicontinuous extraction; ultrasound-assisted extraction; response surface methodology

\section{Introduction}

In the general context of the United Nations Agenda 2030 for Sustainable Development, the recovery of bioactive compounds from food processing by-products and their reuse in the food chain contribute to the optimal use of the raw materials produced (Galanakis, 2020). The recovery of bioactive compounds such as vitamins, lipids, phenolic compounds furthermore corresponds to the growing consumer interest in nutrients that play a role in improving health, maintaining well-being, improving immunity and thus preventing and treating specific diseases (Kumar et al., 2017, Galanakis, 2020).

Walnut (Juglans regia L.) is the most widespread tree nut in the world, presently cultivated commercially throughout southern Europe, northern Africa, eastern Asia, United States and western South America (Martinez et al., 2010). The walnut production is increasing by 5\% per year and reached 3.6 million tons in 2018, half of which produced in China, 30\% in USA, and 11\% in France. (Persistence Market Research 2018, FAOstat). The walnut is a kernel categorized as a strategic species for human nutrition since it is a rich source of different valuable chemicals like proteins, oil, fibers, and minerals (Jahanban-Esfahlan et al., 2019, Ozcan, 2009).

Walnut oil, rich in $\omega-3, \omega-9$, and $\omega-6$ fatty acids, has long been known for its nutritional qualities but is also used in a variety of health and personal care products and in aromatherapy (Persistence Market Research 2018). The oil extraction process consumes twice as many walnut kernels in mass as it produces oil in volume. The production therefore releases huge quantities of partially defatted walnut cake which are often disposed of without any economic benefit or used as animal feed or fertilizer (Li et al., 2017). As with the composition of walnut kernels (Zheng et al., 
2020), the composition of the press-cake will depend on the cultivar, environmental factors, cultivation practices, and on the oil recovery processes as well, but it is still remarkably rich in oil (20-36\%), proteins (30-42\%), dietary fibre, phenolic substances and minerals (Bakkalbasi et al., 2015, Li et al., 2017, Santos et al., 2018, Martinez et al., 2010). Attempts have been made to increase the valorization level of walnut cake, e.g. by incorporating it into meat, dairy and bakery products (Martinez et al., 2010, Bakkalbasi et al., 2015), by using their proteins as carriers of water-insoluble bioactive compounds (Moghadam et al., 2020) or as precursors of active peptides (Liu et al., 2013; Li et al., 2017; Gu et al., 2015). Due to the polyunsaturated fatty acids of the oil, the press cake is sensitive to oxidation, especially when ground into a fine powder. However, it has been shown that flour could be stored for up to 26 weeks without major changes in peroxides levels (Vanhanen and Savage, 2006). This behavior was attributed to the high vitamin E content of the cake which can reach $174 \mathrm{mg} / \mathrm{kg}$ (Bakkalbasi et al., 2015) but other antioxidants such as phenolic compounds may contribute to oxidative stability (Fukuda et al., 2003) since most of the phenolics initially present in the walnut kernels remain in the cake after cold pressing (Bakkalbasi et al., 2015, Arranz et al., 2008, Fukuda et al., 2003, Santos et al., 2018, Fregapane et al., 2020). Walnut press-cake could therefore be harnessed as a source of phenolic antioxidants. The concentration of phenolics in press-cakes is generally between 10 and 20 g GAE/kg (Ojeda-Amador et al., 2018, Arranz et al., 2008, Santos et al., 2018) although a value of $58 \mathrm{~g} \mathrm{GAE} / \mathrm{kg}$ has been reported once (Bakkalbasi et al., 2015). The phenolic compounds present in the walnuts are mainly hydrolysable tannins and phenolic acids, the former accounting for $60-80 \%$ depending on the nut variety, while the flavonols vary from $26-35 \%$ (Ojeda-Amador et al., 2018). The ranking of phenolic families identified in kernels is kept in the corresponding press-cake (Ojeda-Amador et al., 2018, Fregapane et al., 2020). More information on phenolic compounds in nuts (almonds, walnuts, hazelnuts, peanuts, pistachios, macadamia and Brazil nuts) is available in Bodoira and Maestri, 2020, while the case of the walnut is more specifically described by Jahanban-Esfahlan et al. (2019), including the distribution of phenolic compounds in 
the different parts of the fruit. In addition, broader overviews in extraction and bioactivity of phenolic compounds can be found in Mojzer et al., 2016 and Kumar et al., 2017.

The performance of an extraction depends on several external parameters such as temperature, time, solid-solvent ratio, and on parameters inherent to the matrix and the solutes to be extracted such as solubility, particle size and porosity, or chemical solute-matrix interactions. Methanol, ethanol, acetone, ethyl acetate, water and mixtures thereof are common solvents for the extraction of phenolic compounds from plant materials (Dai and Mumper, 2010), including for the preparation of walnut extracts (Jahanban-Esfahlan et al., 2019, Bodoira and Maestri, 2020). Macerations at room temperature in methanol:water (Bakkalbasi, 2019, Labuckas et al., 2008) or ethanol:water (Labuckas et al., 2008, Fregapane et al., 2020), possibly at higher temperature (Santos et al., 2018) have been used to quantify phenolics in walnut by-products. However, the optimization of extraction conditions has rarely been addressed. Extraction efficiency can be improved by using innovative technologies (Chemat et al., 2020, Martinez et al., 2021) based, for example, on the application of electromagnetic waves (microwave assisted extraction MAE, Rosa et al., 2017), ultrasonic waves (ultrasound assisted extraction UAE; Fadimu et al., 2020) and pulsed electric fields or high-voltage electric discharges (Barba et al., 2015). Ultrasound-assisted extraction consists of the application of ultrasonic waves that cause expansion and compression cycles in which the expansion creates liquid bubbles while the compression leads to bubbles collapse, causing cavitation. Cavitation causes cell rupture near the solid surface, which improves solvent penetration and can also break down cell walls. Ultrasounds assistance has been shown to intensify the recovery of phenolic compounds from walnut shell (Han et al., 2018) or walnut husk (Tabaraki and Rastgoo, 2014) but has not increased the phenolic content of extracts obtained from pistachios (Fregapane et al., 2020). On a defatted walnut flour, Luo et al. (2017) combined ultrasound and microwave-assisted extraction to obtain a maximum yield of 34.91 mg GAE/g of flour. Other intensification techniques such as pressurized solvents or supercritical carbon dioxide have been marginally investigated for nuts, although they are increasingly implemented for the recovery of phenolics from fruits or by-products (Gallego et al., 2019, Garcia- 
Salas et al., 2010, Espinosa-Pardo et al., 2017, Garcia-Mendoza et al., 2017, Massias et al., 2015, Garcia-Mendoza et al., 2015, Bursać Kovačević et al., 2018, Goncalves Rodrigues et al., 2019). Extractions by supercritical $\mathrm{CO}_{2}(\mathrm{SCE})$, ultrasound and microwave were optimized for the recovery of phenolics from hazelnut skins (Odabas and Koca, 2015). The extracts obtained by UAE under optimal conditions had the highest total phenolic content and antioxidant activity compared to the extracts obtained by MAE, SCE and reference maceration under maximal conditions. More specifically for walnut by-products, phenolic compounds were extracted from the green husk of the nuts by $\mathrm{CO}_{2}$ technology (Seabra et al., 2019) and from the wooden layer between the nut seeds by pressurized hot water or methanol (Kamali et al., 2018).

The addition of natural antioxidants to lipid-rich food is a promising strategy to avoid lipid deterioration without using synthetic compounds (Jacobsen et al. 2008, Galanakis, 2018, Kalogianni et al., 2020). The enrichment of oils with antioxidant extracts has attracted attention (ReboredoRodríguez et al. 2017, Flori et al. 2020, Romeo et al. 2020). For example, the addition to virgin olive oils of a phenolic extract recovered from olive leaf (Delgado-Adamez et al., 2014) or from olive cake (Suarez et al., 2011) increased oxidative stability by 50\% and $65 \%$ compared with the control oil. In both cases, oxidative stability was further increased by about $40 \%$ and $12 \%$, respectively, by incorporating lecithin into the oils. With regard to the potential of nut extracts, Fregapane et al. (2020) found that olive, pistachio and walnut oils enriched with pistachio or walnut extracts had significantly higher oxidation stability than virgin oils. A 2.4-fold higher oxidation stability was obtained for walnut oil enriched with walnut cake extracts with a concentration of $518 \mathrm{mg}$ phenolics $/ \mathrm{kg}$ oil. The authors also reported that walnut extracts had a higher protective effect against lipid oxidation than pistachio extracts. Although each polyphenol has its own activity (Ho et al., 2020), it is generally the synergy between compounds, even minority ones, that is responsible for the overall activity of an extract. Each extract can therefore, by its variable composition, induce a variable response. The effect of the enrichment level on the oxidation stability of walnut oil was evaluated by Bakkalbasi (2019). A significant decrease in oxidation markers was observed in oils enriched with 50 to $200 \mathrm{mg}$ phenolic 
extract/kg oil, and the protective effect was found to be dependent on the walnut extract concentration. Also dealing with walnut oil, Grosso et al. 2018 evaluated the performance of walnut extracts when separated into two fractions, ethyl acetate-soluble polyphenols on the one hand, and water-soluble polyphenols on the other hand. The two extracts added at $1 \mathrm{~g}$ extract/kg oil helped to preserve the walnut oil against deterioration processes, and in some cases, showed a better performance for quality preservation compared with synthetic BHT. The effectiveness of the ethyl acetate-soluble extract has also been demonstrated when incorporated into an edible coating made from walnut cake protein to protect a solid food, in this case walnut kernels (Grosso et al., 2020).

Our team is currently developing biorefinery schemes for oleaginous by-products (EspinosaPardo et al., 2020). Walnut press-cake is emerging as a cheap source of phenolic compounds that also contains a significant amount of nutritional grade oil. The press-cake used in this work came directly from the oil mill and was only partially defatted. It was further de-oiled by solvent to recover the residual oil and the residue was subjected to ultrasounds extraction (UAE) in prospects of recovering the phenolic compounds. In a context of circular economy, the more stages of treatment, the higher the costs. De-oiling may not be necessary. The extraction of the phenolic compounds was therefore carried out on the raw press-cake by conventional maceration, and by a semi-continuous process in order to highlight different limitations to mass transfer, if any. An overview of the investigations is provided in Fig.1. The efficiency of extraction depends on many factors. In this work, different conditions were investigated with special attention to time and solid-solvent ratio parameters, which are parameters rarely studied in the literature related to nuts. All extracts were characterized for the total phenolics content while antioxidant activity was evaluated for extracts obtained by maceration or ultrasound assistance. In addition, the ability of extract to prevent oxidation of camelina oil was evaluated.

\section{Fig 1}


155

156

157

158

159

160

161

162

163

164

165

166

167

168

169

170

171

172

173

174

175

176

177

\subsection{Walnut cake}

The pressed cake was kindly donated by the Moulin de la Veyssière, Dordogne, France (www.moulindelaveyssiere.fr). The fruits (Lara variety) were grown locally and the kernels were pressed under mild heating to recover the oil. The partially defatted cake was collected the day after pressing and was stored at $-18^{\circ} \mathrm{C}$ after having spent about $48 \mathrm{~h}$ at room temperature. When extraction campaigns were planned, $100 \mathrm{~g}$ were grounded with a coffee grinder, sieved below $600 \mu \mathrm{m}$ (Retsch, Germany) and divided into smaller batches stored at $-18^{\circ} \mathrm{C}$ until use. A sample of the freshly pressed cake was stored at room temperature in a food-grade kraft paper bag after gentle deagglomeration to mimic the storage conditions of flour in mills. The proximate composition of walnut press-cake was analyzed and the results were as follows: moisture (3\%), protein $(27 \%)$, oil (37\%), ash (5\%), carbohydrates $(28 \%)$. The oil content was determined by Soxhlet extraction, as described in 2.3.1., while the moisture content was measured by weight loss during drying at $105^{\circ} \mathrm{C}$ by halogen heating, the ash content by incineration at $500^{\circ} \mathrm{C}$ for $24 \mathrm{~h}$, protein content by the Kjeldahl method using a conversion factor of 5.3, and the carbohydrate content was estimated by mass difference.

\subsection{Solvents and reagents}

Hexane used for de-oiling cakes and ethanol used for phenolics extractions were purchased from Atlantic Labo (Bruges, France). Deionized water with a resistivity of $15 \mathrm{~m} \Omega . c m$ (ELGA, Purelab® Option, UK) was used to prepare ethanol:water mixture. Folin reagent, sulfuric acid, anthrone, glucose, gallic acid, were from Sigma Aldrich (St Quentin Fallavier, France). The phospholipids used in this work (Lipoid P100) was purchased from Lipoid GmbH, France. Lipoid P100 are natural phospholipids derived from non-GMO soybean plants comprising $95 \mathrm{wt} \%$ of phosphatidylcholine. 


\subsubsection{Complete defatting}

181 The walnut pressed cake WAC was further defatted by using boiling hexane in a commercial enhanced design Soxhlet apparatus (Tecator Soxtec ${ }^{\mathrm{TM}}$ HT2, FOSS, Denmark). A sample of $14 \mathrm{~g}$ of raw material was loaded in a Soxhlet thimble and extracted for 4 hours. The solvent was then evaporated from the aluminium extraction beaker and the recovered oil was weighed. The defatted walnut cake (DEWAC) was left in a fume hood overnight to evaporate the remaining solvent and then stored in sealed containers at $-18^{\circ} \mathrm{C}$ until use. The oil content of the walnut cake (NLC $\mathrm{WAC}_{\mathrm{C}}$ ) was $37.25 \pm 0.8 \%$.

A $2^{4-1}$ fractional factorial design was employed to determine the influence of two levels $(-1,+1)$ of extraction time $\left(Z_{1}\right)$, temperature $\left(Z_{2}\right)$, solid-to-solvent ratio $\left(Z_{3}\right)$ and percentage of phosphatidylcholine in the solvent $\left(\mathrm{Z}_{4}\right)$ on the extraction of total phenolic compounds (TPC) and free radical scavenging activity $(\mathrm{DPPH})$ of extracts. The addition of phospholipid to the extracting solvent was motivated by the fact that phospholipids could enhance the recovery of hydrophilic antioxidants (Li et al., 2015) or improve their solubility or dispersion in oil (Garcia-Mendoza et al., 2021, Suarez et al., 2011). The $Z_{4}$ factor was aliased with the second order interaction $Z_{123}$ giving an experimental design of resolution IV. Additional center points (level 0) were added to assess the reproducibility of experiments, to check the absence of drift and to verify the linearity of the responses. The current design comprised 11 experimental runs including 3 center points (level 0) as shown in Table 1. Globally, WAC (3 g) was extracted in a sealed glass flask with 39, 57 or $75 \mathrm{~mL}$ of EtOH60 that provided mass-to-solvent ratios of $1: 13,1: 19$ or $1: 25(\mathrm{~m} / \mathrm{v})$, respectively. The mixture was continuously agitated in a digital magnetic hotplate stirrer with temperature control (Model C-MAG 
$60^{\circ} \mathrm{C}$. Prior to extraction, various amounts of soy phosphatidylcholine were dissolved in EtOH60 for providing the concentrations of Lipoid of $0,0.75 \%$ or $1.5 \%(\mathrm{~m} / \mathrm{v})$.

At the end of the extraction, the sample was transferred to Falcon graduated tubes and centrifuged (Rotanta $460 \mathrm{RF}$, Hettich, Germany) at $13300 \mathrm{~g}$ for $6 \mathrm{~min}$. The supernatant was then filtered on a $0.45 \mu \mathrm{m}$ PVDF syringe filter (Rotilabo-syringe filters, Carl Roth, Germany) and finally stored in amber flask at $-18^{\circ} \mathrm{C}$ until analysis of TPC and antioxidant activity.

\subsubsection{Ultrasound assisted extraction (UAE) on defatted walnut press cake (DEWAC)}

DEWAC (5 g) was placed into a $100 \mathrm{~mL}$ plastic beaker containing $64 \mathrm{~mL}$ of EtOH60 and the extraction was then conducted in an Ultrasonic processor (Sonifier Analog 450, Branson, USA) provided with a $12.7 \mathrm{~mm}$ diameter probe. The probe was immersed to half the height of the sample. After extraction procedure, the sample was centrifuged (Rotanta $460 \mathrm{RF}$, Hettich, Germany) at 13 $300 \mathrm{~g}$ for $6 \mathrm{~min}$, the supernatant was then filtered on a $0.45 \mu \mathrm{m}$ PVDF syringe filter (Rotilabo-syringe filters, Carl Roth, Germany) and finally stored in amber flask at $-18^{\circ} \mathrm{C}$ until further analysis.

A central composite design was chosen to study the influence of theoretical power $(\mathrm{W})\left(\mathrm{X}_{1}\right)$, time $(\mathrm{min})\left(\mathrm{X}_{2}\right)$ and duty cycle $(\%)\left(\mathrm{X}_{3}\right)$ on the extraction of total phenolic compounds (TPC) and the free radical scavenging activity (DPPH) of extracts. The current design comprised 20 experimental runs with 5 levels $(-\alpha,-1,0,+\alpha,+1)$ for each factor as shown in Table 2. Star points were done at -1.68 level in order to have a rotatable design. The levels of the independent factors were chosen according to the operational limitations of the sonifier and the duty cycle was set as the fraction of a period of one second in which the system is active. All ultrasound assisted extractions were carried out at room temperature $\left(24 \pm 1^{\circ} \mathrm{C}\right)$ and at a fix solid-to-solvent ratio $(1: 13 \mathrm{~m} / \mathrm{v})$. Room temperature was selected to limit energy consumption. For avoiding a temperature rise during extraction, the plastic beaker containing the sample was immersed in ice. 
228 A second set of experiments was carried out to investigate the solid:solvent ratio, increasing it from $1: 13$ to $1: 200 \mathrm{~m} / \mathrm{v}$. Other conditions were set at $220 \mathrm{~W}, 20 \mathrm{~min}$ and $40 \%$ for ultrasounds power, extraction time and duty cycle, respectively.

The evaluation of the predicted model was done adjusting the response variable to a second-order polynomial model equation by response surface methodology using the freeware RStudio (RStudio ${ }^{\circledR}$, USA).

$$
Y=\beta_{0}+\sum_{i=1}^{3} \beta_{i} X_{i}+\sum_{i=1}^{3} \beta_{i i} X_{i}^{2}+\sum_{i=1}^{3} \sum_{j=1}^{3} \beta_{i j} X_{i} X_{j}
$$

where $Y$ represents the response variable (total phenolic extraction or free radical scavenging activity); $\beta_{0}, \beta_{i}, \beta_{i i}$ and $\beta_{i j}$ are the intercept, linear, quadratic and interaction coefficient, respectively; $X_{i}$ and $X_{j}$ are the independent factors affecting the response. In order to identify the significant terms, an analysis of variance (ANOVA) has been performed with a confidence level of $95 \%$.

\section{Extraction}

The semi-continuous extractions were carried out by flowing the solvent through a bed of walnut cake particles and collecting periodically the effluent in graduated tubes. Conditions of temperature $\left(60^{\circ} \mathrm{C}\right)$ and total volume of solvent $(25 \mathrm{~mL}$ per gram of WAC) were selected from the WAC-MA batch investigations. Five grams of walnut cake were mixed with an inert filler made of glass beads of $2 \mathrm{~mm}$ or $0.5-0.75 \mathrm{~mm}$ prior being loaded in a column of $19.8 \mathrm{~cm}$ height $\mathrm{x} 0.9 \mathrm{~cm}$ internal diameter. The bed was overtopped by glass beads to completely fill the column. The column was placed in an oven (Shimadzu CTO-SA, Japan) to control the temperature. The solvent, heated at $60^{\circ} \mathrm{C}$ by a magnetic hotplate stirrer with temperature control (model C-MAG HAS, Ika ${ }^{\circledR}$, Germany), was 
252 delivered at $1.0 \pm 0.05 \mathrm{~mL} / \mathrm{min}$ by a dual pump (Waters $515 \mathrm{pump}$, Saint-Quentin-en-Yvelines, 253 France). At the column exit, a capillary drove the effluent to a graduated tube $(10 \mathrm{~mL}$, accuracy 0.2 $254 \mathrm{~mL}$ or $25 \mathrm{~mL}$, accuracy $0.5 \mathrm{~mL}$ ) immersed in ice. The graduated tube was changed periodically to 255 collect 6 fractions of $7 \mathrm{~mL}, 7 \mathrm{~mL}, 7 \mathrm{~mL}, 22 \mathrm{~mL}, 44 \mathrm{~mL}$ and $44 \mathrm{~mL}\left(V_{i} \mathrm{~mL}\right)$, respectively, for the 256 entire extraction time of $140 \mathrm{~min}$.

\section{Extracts processing and characterization}

259 Once collected, the fractions were transferred to round flasks. An aliquot of $2 \mathrm{~mL}$ was sampled for 260 quantification of total phenolic compounds, while the remainder was vacuum desolvated at $95 \mathrm{kPa}$. 261 The amount extracted in each fraction $\left(Q_{i}, \mathrm{~g}\right)$ was quantified by the weight obtained after rotavapor 262 multiplied by the volume factor $\mathrm{V}_{\mathrm{i}} /\left(\mathrm{V}_{\mathrm{i}}-2\right)$ to account for the $2 \mathrm{~mL}$ aliquots. The results are given as 263 cumulative extracted quantities per $\mathrm{g}$ of walnut cake.

264 The $2 \mathrm{~mL}$ aliquots were analyzed for total phenolic content (TPC) according to the procedure 265 described in 2.4. The aliquots were first vortexed and, depending on the presence of agglomerates or 266 oil, the samples were filtered on PVDF 0.45 micron or/and centrifuged at $10000 \mathrm{~g}$ for $20 \mathrm{~min}$. Each 267 sample was analyzed in duplicate.

\section{Modeling extraction kinetics}

The extraction kinetics of the phenolic compounds and the total extracted amount were modeled by

271 a two-sites kinetic desorption model (Kubatova et al., 2002). The model considers that a fraction of 272 the extractable compounds is located close to the surface of particles and is therefore easily 'washed' 273 by the solvent, while the remaining fraction, located inside the matrix particles, is less accessible and 274 is therefore desorbed at a slower rate. The model is derived from the Fick's law of diffusion like many 275 others (Dagostin et al., 2015, Mosca et al., 2018, Subra et al., 1998) but here an overall rate $k$ is used 
276 in the exponential term instead of the diffusion coefficient because the particles are likely not uniform 277 in shape or in size. Extraction kinetics were fitted to the following model:

$$
y_{t}=y_{\infty}\left[1-f e^{-k_{1} t}-(1-f) e^{-k_{2} t}\right]
$$

where $y_{t}$ is the yield (cumulated extracted amount $/ \mathrm{g}_{\mathrm{WAC}}$ ) or TPC (mg GAE/gWAC), $y_{\infty}$ is the concentration at saturation (g extract/ $\mathrm{g}_{\mathrm{WAC}}$ or $\mathrm{mg} \mathrm{GAE} / \mathrm{g}_{\mathrm{WAC}}$ ), $f$ is the fraction of extractable material 281 of easy access, $t$ is the extraction time, $k_{l}$ is the first-order rate constant describing the quickly released 282 fraction $\left(\mathrm{min}^{-1}\right)$, and $k_{2}$ is the first-order rate constant describing the slowly released fraction $\left(\mathrm{min}^{-1}\right)$. 283 The model was fitted to the experimental data using Microsoft Excel Solver, minimizing the mean 284 relative percent deviation.

The cake after COL extraction was submitted to hexane Soxhlet extraction to quantify its residual content in oil. The \{glass beads + WAC \} mix was loaded in the Soxhlet thimble and extracted by hexane as described in section 2.3.1. The oil recovered by Soxhlet $\left(Q^{\prime}{ }_{\text {oil }}, \mathrm{g}\right)$ was weighted and the amount of oil previously extracted by COL was calculated as the difference between the amount of oil initially present in WAC and the oil recovered by Soxhlet:

$\operatorname{Oil}_{\text {by COL }}(g)=N L C_{W A C} M_{W A C}^{\prime}-Q_{o i l}^{\prime}$

in which M'WAC (in g) is the mass of walnut cake submitted to COL extraction, NLCWAC the lipid content of the walnut cake and Q' ${ }_{\text {oil }}$ the amount of oil recovered by Soxhlet. 
TPC of extracts were measured using the Folin-Ciocalteu assay. Firstly, $50 \mu \mathrm{L}$ of extract or standard solution were added to $800 \mu \mathrm{L}$ of distilled water and after the addition of $50 \mu \mathrm{L}$ of Folin-Ciocalteu reagent the samples were vortexed. After $3 \mathrm{~min}, 100 \mu \mathrm{L}$ of $\mathrm{Na}_{2} \mathrm{CO}_{3} 1 \mathrm{~N}$ solution was added to the mixture. The solutions were incubated for $2 \mathrm{~h}$ in absence of light, and the absorbance was then read at $725 \mathrm{~nm}$ on a multimode microplate reader (Spark ${ }^{\circledR} 10 \mathrm{M}$, Tecan, Switzerland). Gallic acid was used as standard and a calibration curve was plotted in a concentration range of $16-350 \mathrm{mg} / \mathrm{L}$. All analyses were performed in triplicate and the TPCs were expressed as mg of Gallic Acid Equivalents $(\mathrm{GAE}) / \mathrm{g}$ of raw material.

\subsubsection{Free radical scavenging activity (DPPH)}

The antioxidant activity of the extracts was evaluated based on the scavenging activity of the 2,2diphenyl-1-picrylhydrazyl (DPPH) free radical (Espinosa-Pardo et al. ,2017). Solutions consisting of $50 \mu \mathrm{L}$ of extract or standard solution and $150 \mu \mathrm{L}$ of $0.2 \mathrm{mM}$ DPPH in methanol, were analyzed on a multimode microplate reader $\left(\operatorname{Spark}^{\circledR} 10 \mathrm{M}\right.$, Tecan, Switzerland) with absorbance filters for a wavelength of $520 \mathrm{~nm}$. The decoloring process was recorded during $35 \mathrm{~min}$ of reaction and the measures were performed in triplicate. The antioxidant activity was calculated using a calibration curve of Trolox ${ }^{\circledR}$ at different concentrations in a range of 7-300 $\mu \mathrm{mol} / \mathrm{L}$ and DPPH was expressed as $\mu \mathrm{mol}$ of Trolox Equivalent /g of raw material (Trolox Equiv./g).

\subsubsection{Oil enrichment and oxidative stability assessment}

The extract $\mathrm{n}^{\circ} 10$ obtained during WAC maceration was used for enriching camelina oil (Coil) at concentrations of 150 and $1500 \mathrm{mg}$ extract/kg oil, in presence or absence of phospholipids (Lipoid P100). For oil enrichment, $1.4 \mathrm{~mL}$ or $14 \mathrm{~mL}$ of extract was directly added to $70 \mathrm{~g}$ of oil co-enriched or not with phospholipids at $20 \mathrm{mg} / \mathrm{g}_{\text {oil }}$, except for the case of $1500 \mathrm{mg}$ extract $/ \mathrm{kg}$ and $20 \mathrm{mg} / \mathrm{g}$ Lipoid 
P100 where the extract was first concentrated from 14 to $1.5 \mathrm{~mL}$ under nitrogen flux. The samples were gently homogenized and the solvent was then removed in a rotary evaporator (Model RE 300DB, Stuart, UK). The enriched Coil was agitated at room temperature $\left(24 \pm 1^{\circ} \mathrm{C}\right)$ for $1 \mathrm{~h}$ on a digital magnetic stirrer (Model C-MAG HS 7, Ika ${ }^{\circledR}$, Germany). After enrichment procedure, the oils were submitted to accelerated oxidation.

The oxidative stability of enriched Coil was studied through the Schaal oven test. For that, $7 \mathrm{~g}$ of enriched oil were placed in $40 \mathrm{~mL}$ sealed amber flasks and submitted to accelerated oxidation at $60^{\circ} \mathrm{C}$ in a laboratory oven (DRY-Line, VWR, UK) for several hours. The amber flasks containing the $7 \mathrm{~g}$ of oil were periodically collected and stored at $-80^{\circ} \mathrm{C}$ until analysis. Both enriched and non-enriched Coil were oxidized in duplicate and the oxidation was monitored by conjugated dienes (CD) analysis.

\section{Results}

\subsection{Maceration (MA) on walnut cake WAC}

The coded values of variables and the responses of the fractional factorial experiments are reported in Table 1. Runs 1, 6 and 11 comprised the three replicates at the central point.

\section{Table 1}

For the total phenolic content, values between 2.2 and $14.8 \mathrm{mg} \mathrm{GAE} / \mathrm{g}_{\text {meal }}$ were obtained with a mean value of $8.9 \mathrm{mg} \mathrm{GAE} / \mathrm{g}_{\text {meal }}$. The highest values are consistent with those reported by Ojeda-Amador et al., $2018\left(19 \mathrm{mg} / \mathrm{g}_{\mathrm{meal}}\right)$ for a cake from Lara variety kernels, considering that extraction of phenolic compounds was performed at a solid-to-solvent ratio of 1:50 which is a variable influencing the extraction yield. Higher values can be found in literature, as $19-35 \mathrm{mg} / \mathrm{g}_{\text {meal }}$ for instance (Luo et al., 2017), but the cake was obtained from another variety and extractions were carried out with simultaneous microwave and ultrasonic assistance. The statistical analysis through multiple regression and ANOVA (supplementary data S1) revealed that temperature $\left(Z_{2}\right)$, solid-to-solvent ratio $\left(Z_{3}\right)$, phospholipid concentration in the solvent $\left(Z_{4}\right)$ and binary interactions of temperature with 
349 phospholipid concentration $\left(Z_{24}\right)$ and with solid-to-solvent ratio $\left(Z_{23}\right)$ were significant at $95 \%$ level.

350 The best model fitting the experimental data was determined using a backward-forward AIC criterion 351 (Akaike, 1974). Such model includes time $\left(Z_{l}\right)$ as factor in addition to the significant terms and reads 352 as (expressed in coded values):

$\mathrm{TPC}=8.9+0.7 Z_{1}+2.4 Z_{2}+1.4 Z_{3}-3 Z_{4}+1.4 Z_{24}+Z_{23}$

The model explained $95 \%$ of the experimental variance and showed that the effect of phospholipid concentration was negative. Adding PL to the solvent was hence deleterious to the extraction of TPC whereas increasing temperature, ratio and time improved it. The 3D response surface plots (Fig.2) illustrates the trends between TPC response and extraction parameters, as temperature and solid-tosolvent ratio in one hand, temperature and phospholipids concentration in the other hand. The conditions maximizing the TPC were therefore 60 minutes of extraction at $60^{\circ} \mathrm{C}$ with $1: 25$ ratio in absence of PL.

363 For DDPH response, the values ranged from 12 to $137 \mu \mathrm{mol}$ Trolox Equiv./gmeal with a mean of $36477 \mu \mathrm{mol}$ Trolox Equiv./gmeal. As for total phenolic content, the highest values are consistent with 365 Ojeda-Amador' results that reported a value of $149 \mu \mathrm{mol} / \mathrm{g}_{\text {meal }}$ for the cake from the Lara variety 366 (Ojeda-Amador et al., 2018). The best model fitting identified phospholipid concentration and 367 temperature as the unique significant factors at 95\% level (Supplementary data S2). The relevant 368 model explained $78 \%$ of the variability and highlighted the deleterious effect of PL and the positive 369 effect of temperature, as demonstrated by the 3D plots (Fig.2).

371 The conditions maximizing the DPPH were therefore a temperature of $60^{\circ} \mathrm{C}$ and no phospholipids 372 added in the extracting solvent leading to a DDPH value of $137 \mu$ mol Trolox Equiv. /g WAC. 
375 Conditions of run 10 provided the highest extraction yield of phenolic compounds and the highest 376 free radical scavenging activity. To evaluate the extract's antioxidant effectiveness at retarding oil 377 oxidation, the run10-extract was added to camelina oil, pure or pre-enriched with phosphatidylcholine. Camelina oil has a high content of polyunsaturated fatty acids (58.7\%) in which 379 linolenic acid (C18:3 $\omega-3)$ and linoleic acid (C18:2 $\omega-6)$, prone to oxidize easily, represent 37.5 and $17.3 \mathrm{wt} \%$, respectively. The oil oxidation time-course was monitored by quantifying the conjugated dienes $(\mathrm{CD})$ that are intermediary products of the first stage of lipid oxidation produced by the rearrangement of the double bonds of unsaturated fatty acids during the formation of hydroperoxides. The oxidation curves (Fig.3) showed that the extract did retard the oil oxidation even when added at the lowest level of $150 \mathrm{mg} / \mathrm{kg}$. At that level, the effect was significantly potentiated by the addition of phospholipids whereas at higher concentration of extract $(1500 \mathrm{mg} / \mathrm{kg})$, phospholipids exerted only a weak additional benefit. The joint action of extract and phosphatidylcholine could be explained by the ability of phospholipids to stabilize the added phenolic compounds in the oil matrix due to their amphiphile behavior, forming reverse micelles that contain the hydro-alcoholic or the aqueous solution of the extract (Suarez et al., 2011). The oxidation delay can be quantified by considering the conjugated dienes value corresponding to a PV (Peroxide Value) of $15 \mathrm{meqO}_{2} / \mathrm{kg}$ that is the highest PV allowed from the Codex Alimentarius for edible virgin oils, thanks to the linear correlation established between PV and CD for the camelina oil (Garcia Mendoza 2020). The CD value of 0.275 was obtained in $40 \mathrm{~h}$ to $72 \mathrm{~h}$ depending on the formulation, a time which was significantly higher than the $24 \mathrm{~h}$ of the non-enriched oil used as control. The positive effect of walnut extract at improving oxidative stability of an enriched oil confirmed the behavior observed for other oils. In Bakkalbasi 2019, oils enriched with 50, 100 and $200 \mathrm{mg}$ phenolic extract/kg oil were submitted to accelerated oxidation at $65^{\circ} \mathrm{C}$. The total phenol content of the enriched oil varied with the added amount of extract, from 28 to $84 \mathrm{mg}$ GAE $/ \mathrm{kg}$ oil. A PV value of $12 \mathrm{meqO} / \mathrm{kg}$ was reached after about 6.5 days 
9 days for reaching the same PV, which means 1.4-fold greater oxidative stability of enriched oil. In Grosso et al., 2018, a walnut extract that contains $230 \mathrm{mg}$ phenolic/g extract was added to walnut oil at $0.1 \% \mathrm{w} / \mathrm{w}$. With an enrichment level of $230 \mathrm{mg}$ GAE $/ \mathrm{kg}$ oil, a PV of $15 \mathrm{meqO} / 2 \mathrm{~kg}$ was reached in about 6 days which represents a 1.2-fold- increase compared with non-enriched oil. In our camelina oil samples, the enrichment with 150 and $1500 \mathrm{mg}$ extract $/ \mathrm{kg}$ oil led to a TPC of 42 and $130 \mathrm{mg}$ GAE/kg oil, and to a PV value of $15 \mathrm{meqO}_{2} / \mathrm{kg}$ reached after $41 \mathrm{~h}$ and $66 \mathrm{~h}$ of oxidation, respectively. It corresponds to an increase in stability of 1.7 and 2.7 times compared with the control sample, values that are therefore of the same order of magnitude as those of literature.

Fig. 3

\subsection{Maceration assisted by ultrasounds (UAE) on defatted walnut cake DEWAC}

Responses obtained during fractional factorial experiments are reported in Table 2. Experiments were carried out at $\mathrm{T}=24 \pm 1{ }^{\circ} \mathrm{C}$ with a fixed solid-solvent ratio of $1: 13 \mathrm{~m} / \mathrm{v}$. Runs 15 to 20 comprised the six replicates at the central point $\left(\mathrm{X}_{\mathrm{i}}=0\right)$. Both TPC and DPPH were found to vary slightly, between 10.37 and $13.26 \mathrm{mg}$ GAE/gDEWAC and 83 to $107 \mu \mathrm{mol}$ Trolox Equiv. /gDEWAC, respectively.

The backward-forward method was used for determining the best model fitting the experimental data using AIC criterion and the response surfaces for TPC are shown in Fig. 4. The predicted model for the phenolic extraction is given below $\left(\mathrm{X}_{1}\right.$, ultrasound power; $\mathrm{X}_{2}$, time; $\mathrm{X}_{3}$, duty cycle, in coded values),

$$
\mathrm{TPC}=12.33+0.35 X_{1}+0.31 X_{2}+0.54 X_{3}
$$

and it explained $63 \%$ of the variability of phenolic extraction by UAE. It can be stated that the low variation of TPC among the different conditions of UAE influenced significantly the adjusted $\mathrm{R}^{2}$ of 
424 the fitted model. On the other hand, ANOVA results (Supplementary data as S3) showed that the 425 three factors (power, time and duty cycle) significantly influenced the TPC, nonetheless quadratic 426 coefficients and those related to the interactions among the different factors were not significant. The 427 model also showed that the influence of power, time and duty cycle was positive which means that 428 the higher the power, time and duty cycle the higher the TPC. In this sense, conditions maximizing 429 the TPC extraction corresponded to the maximal value of each factor, e.g. $233.6 \mathrm{~W}, 23.4 \mathrm{~min}, 46.8 \%$ 430 duty cycle.

Table 2.

Fig. 4

When antioxidant activities of walnut extracts DPPH were attempted to be predicted by a polynomial model, it only explained $36 \%$ of the variability of the experimental results significant at $\mathrm{p}<0.05$. Therefore, none of the response surfaces was plotted for the different factors. Although the model had a poor adjusted $\mathrm{R}^{2}$, only time and duty cycle appeared as significant factors. Similarly, Odabaş and Koca (2016) also reported a poor adjusted $\mathrm{R}^{2}(0.53)$ of the model generated for predicting the DPPH radical scavenging activity (1/EC50) of hazelnut skin extracts obtained by UAE.

441 On the other hand, it is worth mentioning that a strong positive correlation between TPC and DPPH 442 was observed (0.95 Pearson's correlation coefficient, $\mathrm{p}<0.05)$. The high and positive correlation 443 between the total phenolic content and the antioxidant activity (DPPH) of several plant extracts has 444 been previously reported by other authors (Piluzza and Bullitta, 2011; Gil et al., 2002).

445 The second set of experiments, performed at conditions providing the highest TPC yield, aimed to evaluate the influence of the solid-to-solvent ratio (Fig. 5). Other conditions were set at $220 \mathrm{~W}, 20$ min and $40 \%$ for ultrasounds power, extraction time and duty cycle, respectively. Results showed that phenolics extraction was significantly influenced by the ratio with a value of $29.0 \pm 0.3 \mathrm{mg}$ 
$449 \mathrm{GAE} / \mathrm{g}_{\text {cake }}$ obtained at ratio 1:200, which represented a $121.4 \%$ increase compared with the TPC 450 obtained at 1:13. Solid-to-solvent ratio influences the concentration gradient between the solid and 451 the solvent phases and this was found to enhance the amount of phenolics recovered at a fix extraction 452 time. Data were satisfactorily fitted with a $\log _{\mathrm{n}}$ relationship $\left(\mathrm{R}^{2}\right.$ of 0.984 , dotted line in Fig.5), 453 indicating that TPC extraction yield will slow down at higher ratio. When estimating the amount of 454 phenolics that would be extracted using the ratio of $1: 1000$, we get a value of $38 \mathrm{mg} / \mathrm{g}_{\text {cake, }}$, which 455 would represent a $31 \%$ increase in yield but would require a five-fold increase in solvent 456 consumption.

Fig. 5

\subsection{Semi-continuous extraction (COL) on walnut cake}

The extraction consisted of flowing the solvent through a bed of walnut cake particles and periodically collecting the extracts to monitor the extraction kinetics. The extraction time was adjusted to obtain the same final volume of solvent per mass of solid as under maceration conditions. The use of a larger quantity of cake ( $5 \mathrm{~g}$ ) was motivated by the objective of extracting not only the phenolic compounds, but also the oil, since the cake contains approximately $37.25 \pm 0.8 \%$ oil. While hydroalcoholic solvents are suitable for the extraction of phenolic compounds, ethanol is increasingly considered as a potential solvent to replace hexane in the extraction of vegetable oils (Baümler et al. ,2016, Navarro et al, 2016, Citeau et al., 2018) although the presence of water is detrimental to oil solubility (Sampaio Neto et al., 2018, Sawada et al., 2014, Kwiatkowski and Cheryan, 2002).

471 The extraction kinetics, reported as cumulated amounts of total extract or phenolics per $\mathrm{g}$ of meal, 472 are given in Fig.6 (WAC load : $5.02 \pm 0.02 \mathrm{~g}$, filler of $0.5-0.75 \mathrm{~mm}$ or $2 \mathrm{~mm}, \mathrm{~T}=60^{\circ} \mathrm{C}, \mathrm{F}=1 \mathrm{~mL} / \mathrm{min}$ ). 473 The 'zero' time is when the solvent flow was started and it took about 9-10 min for the solvent to exit 
474

475

476

477

478

479

480

481

482

483

484

485

486

487

488

489

490

491

492

493

494

495

the column. The deviation bars are from the duplicate extractions with the exception of the TPC data from the 'storage at room $\mathrm{T}$ ' essay for which only one of the two extractions was analyzed.

\section{Fig. 6}

For phenolic compounds, the highest TPC value of $19.83 \pm 0.24 \mathrm{mg} / \mathrm{g}_{\mathrm{WAC}}$ was higher than the TPC of $14.78 \pm 0.37 \mathrm{mg} / \mathrm{g}_{\mathrm{WAC}}$ obtained by batch maceration. This could be the result of better contact between the solvent and the matrix in COL trials where the solvent flew through the particulate bed, leading to better mass transfer. A slight difference in the composition of the solvent is not excluded since the hydroalcoholic mixture was prepared with EtOH $96 \%$ instead of absolute ethanol. The higher extraction rate observed when smaller beads were used as filler could be due to better packing and less wall effect which induced more homogenous velocity distributions (Minhua et al., 2018, Zhang et al., 2018). Storage at room temperature leads to slower extraction, but the particle size may contribute to the behavior since the material has not been sieved below $600 \mu \mathrm{m}$. It should be noted that coarse grinding of the cake and storage of the flour at room temperature, which could mimic the conditions under which flour should be sold, maintained about $77 \%$ of the phenolic compound content. Several studies have tested the influence of packaging materials and storage conditions on physicochemical properties and quality of walnut kernels (Adiletta et al., 2020; Ahad et al., 2020). Ahad et al. reported for instance a decrease of TPC from $31.2 \mathrm{mg} \mathrm{GAE} / \mathrm{g}$ to $18.8 \mathrm{mg}$ GAE/g, which represents a loss of $60 \%$ after 270 days of storage at ambient conditions under relative humidity of $80 \%$. In our study, the loss was only $23 \%$. The partially de-oiled flour with a moisture content of $3 \%$ therefore seems to better maintain its phenolic potential than fresh kernels.

Data in Fig.6 also show that none of the extraction curves reached a plateau, indicating that extractions were not completed after 140 minutes. Extraction rates nevertheless slowed down after 95 minutes, e.g at a solid/solvent ratio of 1:19. To better address extraction mechanisms, extraction 
kinetics were modelled using a two-step approach (Table 3). Although the regression coefficients were greater than 0.98 , the model better fit the kinetics of the "room temperature storage" case, probably due to the larger number of experimental data. For the other two conditions, the absence of an experimental plateau in the kinetic curves affected the accuracy of the $Y_{\infty}$ estimate. Considering that $Y_{\infty}$ corresponds to the maximum extractable quantity (Mosca et al., 2018), the same value of $21.8 \mathrm{mg} / \mathrm{g}$ found by optimizing the model variables of the "storage $-18^{\circ} \mathrm{C}$ - filler $0.5 \mathrm{~mm}$ " trial was used to model the kinetics of the 2 mm-beads. Differences were observed in the fraction of easily extractable compounds $(f)$ or in the $k_{l}$ values, but this easy washing step concerned less than $9 \%$ of the amount of extractable phenols $(f<0.09)$. Thus, the majority of the phenolic compounds were extracted by a slower diffusion process, which indicated a poor accessibility.

In COL experiments, the overall quantity extracted was also monitored. One of the kinetics reached a plateau at $0.242 \pm 0.06 \mathrm{~g}$ of extract $/ \mathrm{g}_{\mathrm{WAC}}$. As for phenolics, the use of $0.5 \mathrm{~mm}$ beads improved the extraction rate, while the matrix stored at room temperature and not sieved released the extractable compounds more slowly. As shown in Fig.6, the two-sites model using a single $Y_{\infty}$ concentration corresponding to the plateau correctly predicted all three kinetics. In contrast to phenolics, the major part of extractable compounds was easily accessed by the solvent at a rate $k_{l}$ that was significantly higher than the desorption of the less accessible solutes ( $k_{2}$ values). For the sample stored at room temperature, the $f$ value was lower but the lack of experimental points at short times probably hampered the fit for this step.

\section{Table 3}

With a fairly polar extracting solvent, a wide variety of molecules such as proteins, carbohydrates, phospholipids can be solubilized. Some triglycerides and free fatty acids can also be extracted, although the high water content of the extraction solvent impairs their solubility. The identification 
524 of the extracted classes was out of scope, however, extraction of lipids can be assessed by analyzing 525 the walnut cakes after COL experiments for their oil content (as described in 2.3.5). The data 526 presented in Fig.7 show that the hydro-alcoholic mixture effectively extracted about $30 \%$ of the oil 527 present in the press-cake and that the storage and diameter of the beads had no major effect on the 528 amount of oil extracted. A closer look at the aliquots of the fractions collected during extraction of 529 the test 'storage $-18^{\circ} \mathrm{C}$; filler $0.5 \mathrm{~mm}$ ' (Fig. 8) showed that the oil was not uniformly extracted during 530 the course of extraction but was especially concentrated in the first fraction. Since the kernels were 531 already crushed to extract the virgin oil, the oil remaining in the press-cake could be easily accessible 532 by the solvent, which explains the high values of the kinetic parameters $f$ and $k_{l}$ obtained for the 533 overall extracts.

\section{Discussion}

539 In this work, the material from which phenols were recovered was a walnut press-cake obtained from an artisanal oil production mill. The cake (WAC sample) was therefore a partially de-oiled material that still contained about $37 \%$ oil. It was further de-oiled by hexane extraction to obtain the DEWAC 542 sample.

543 Phenolic compounds were first extracted from WAC by batch maceration under stirring, changing 544 the temperature, solid-solvent ratio and time from $28^{\circ} \mathrm{C}$ to $60^{\circ} \mathrm{C}$, from $1: 13$ to $1: 25 \mathrm{~m} / \mathrm{v}$ and from 15 545 to $60 \mathrm{~min}$, respectively, and considering enrichment of the solvent by phospholipids at $1.5 \mathrm{wt} \%$ as an 546 additional option. The yield of extracted phenolic compounds ranged from 2.2 to $14.8 \mathrm{mg} \mathrm{GAE} / \mathrm{g}_{\text {cake, }}$ 547 the lowest value being obtained at $28^{\circ} \mathrm{C}$ in the presence of phospholipids. Otherwise, the yield of

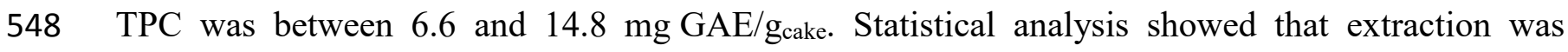


enhanced by temperature, solid-solvent ratio and time while the presence of phospholipids was deleterious. The effect of the first three parameters is quite common in extraction. A higher temperature increases the solubility and diffusion of the solutes in the solvent while reducing the viscosity of the solvent; a higher solid:solvent ratio gives a higher concentration gradient at the surface of the solid which is the driving force of mass transfer, and reduces the risk of solvent saturation; a longer time would improve recovery when extraction is limited by mass transfer, especially from intra-particle diffusion. The deleterious effect of phospholipids is striking. Either phospholipids act as an antisolvent, i.e. they decrease the solvating capacity of the aqueous ethanolic solvent for the main representative phenols, ellagitannins and flavonols, or they acted as a barrier by trapping the phenols inside the matrix or preventing the solvent from accessing them. On the other hand, phospholipids are amphiphilic molecules commonly used in oil-in-water and water-in-oil emulsions because they are positioned at the water-oil interface. Contrary to the anti-solvent effect, if strong interactions occur between phenolic compounds and the polar fragments of phosphatidylcholine (glyceride skeleton, phosphate and amine groups), the hydrophobic tails of the phospholipids would drag the polar complex close to the oil droplets (part of the oil has indeed been extracted by the hydro-alcoholic solvent, as confirmed by the COL tests), and would form aggregates likely to sediment during centrifugation. The underestimation of TPC was another possible cause as considered by Suarez et al. who hypothesized the formation of small drops of hydro-ethanolic extract solution surrounded by lecithin molecules, a structuring that could prevent the phenols from reacting with the Folin-Ciocalteu reagent (Suarez et al., 2011).

The use of a packed bed of cake particles instead of their suspension allowed a better recovery of phenols (TPC close to $20 \mathrm{mg} \mathrm{GAE} / \mathrm{g}_{\text {cake }}$ ) when a filler with a particle size close to that of the cake was used. In a batch extraction process, the concentration gradients between solvent and solid are lower due to the greater homogeneity of the concentration of the extract in the solvent volume and the mass transfer process is completed when the equilibrium concentration is reached (Mosca et al., 2018). In the semi-continuous process, the fresh solvent flow provides higher concentration gradients 
at the interface and the extraction ends when all the compound is removed (Mosca et al., 2018). The kinetic study highlighted the fact that more phenols could be extracted by increasing the time and, consequently, the solid-solvent ratio. However, from a process point of view, continuing the extraction while the extraction rate slows down is not economically interesting due to the higher solvent consumption and the recovery of increasingly diluted solutions. Quantification of the overall yield and the oil remaining in the residue further confirmed that the hydro-alcoholic solvent was not selective for phenolic compounds alone but extracted up to $32 \%$ of the oil present in the press-cake. The phenolics represented about $8 \%$ by weight of the total accumulated extract at 140 min, while the oil represented $46 \mathrm{wt} \%$.

The intensification of the extraction by using ultrasound was studied on a completely defatted nut cake at $24^{\circ} \mathrm{C}$ using first a mass/solvent ratio of $1: 13$. The effect of ultrasound is to induce an alteration of the cell structure leading to increased solvent penetration. The yield of phenolic compounds varied by a maximum of $30 \%$, with values ranging from 10.4 to $13.4 \mathrm{mg} \mathrm{GAE} / \mathrm{g}_{\text {cake. }}$ Furthermore, the improvement compared to a maceration carried out without ultrasound for 20 minutes at the same temperature and with the same solid/solvent ratio, which gave a value of $9.7 \pm 0.4 \mathrm{mg} / \mathrm{cake}$, was rather small. This could be explained by the relatively narrow range of variables studied here. On the other hand, statistical analysis has shown that increasing the power or duty cycle parameters of the ultrasound should improve extraction efficiency. An additional experiment carried out in another equipment operating at a higher power led to a higher extraction yield, with a TPC value of $19.2 \mathrm{mg}$ $\mathrm{GAE} / \mathrm{g}_{\text {cake }}$ compared to the $14.5 \mathrm{mg} \mathrm{GAE} / \mathrm{g}_{\text {cake }}$ obtained in the absence of ultrasound (solid-solvent ratio of 1:50). To better appraise the differences between the devices, the ultrasound intensity $\left(\mathrm{W} / \mathrm{cm}^{2}\right)$ was quantified by calorimetric measurements. For the sonifier used in the UAE experimental design, the intensity ranged from 0.34 (power of 45 , duty cycle of 20 ) to $4 \mathrm{~W} / \mathrm{cm}^{2}$ (power of 55 , duty cycle of 40), while in the additional experiment the intensity was $54.7 \mathrm{~W} / \mathrm{cm}^{2}$. A higher intensity therefore significantly improved the extraction efficiency. Focusing on UAE of phenolic compounds from defatted hazelnut skins, Odabas and Koca (2016) showed that the most significant variable was 
the concentration of ethanol in the hydro-alcoholic mixture (range between 50 and $90 \%$, maximum efficiency obtained at 65-70\%), followed by the extraction time (ranging between 15 and $45 \mathrm{~min}$ ), while the extraction temperature, ranging between $20^{\circ} \mathrm{C}$ and $60^{\circ} \mathrm{C}$, was not significant. Compared to a maceration trial, the ultrasound assistance resulted in a much higher efficiency with a TPC of 122.9 $\mathrm{mg} \mathrm{GAE} / \mathrm{g}$ under the best conditions instead of $58.8 \mathrm{mg} \mathrm{GAE} / \mathrm{g}$, which represents a 2-fold increase. These extractions were carried out at a ratio of $50 \mathrm{~mL}$ of solvent/g of solid and at a power of $1500 \mathrm{~W}$, which is much higher than the highest power set here. On the other hand, Pingret et al. (2012) obtained a $32 \%$ increase over maceration using a power of $0.7 \mathrm{~W} / \mathrm{cm}^{2}$ (solvent: water, $40^{\circ} \mathrm{C}, 40 \mathrm{~min}$, material: apple pomace, TPC of $5.5 \mathrm{mg}$ catechin equivalent $/ \mathrm{g}$ versus $4.2 \mathrm{mg} / \mathrm{g}$ ), an improvement that is within the range of our data in the UAE experimental set. For another by-product (chicory grounds), a smaller increase of $8 \%$ and $11 \%$ was reported at $20^{\circ} \mathrm{C}$ and $60^{\circ} \mathrm{C}$, respectively, when ultrasounds power was increased from 0 to $100 \mathrm{~W}$ (Pradal et al. 2016; solvent : EtOH 60\%).

Furthermore, the second set of extractions performed under the ultrasound conditions that gave previously the highest TPC yield showed the significant importance of the solid-solvent ratio. By increasing it from 1:13 to 1:200, TPC increased from 13.1 to $29.0 \mathrm{mg} \mathrm{GAE} / \mathrm{g}_{\text {cake, }}$ an improvement of $121 \%$. This behavior was consistent with conclusions drawn from batch and semi-continuous experiments on non-defatted WAC cake that showed the positive effect of either the solid-solvent ratio or time. As previously mentioned, a higher solid-solvent ratio leads to a higher concentration gradient at the surface of the solid, which is the driving force of mass transfer, and decreases the risk of solvent saturation. The fact that both the WAC and DEWAC extractions were influenced by the solid to solvent ratio could suggest that solubility issues are important for the extraction of phenols from walnut and that a ratio of up to $200 \mathrm{~mL}$ of solvent per $\mathrm{g}$ of solid should be considered as a minimum.

Regarding the effect of de-oiling the cake before the extraction of the phenolic compounds, a theoretical TPC was calculated for WAC under the conditions of $24^{\circ} \mathrm{C}, 20 \mathrm{~min}, 1: 13$ used for UAE extraction. The theoretical value of $10.0 \mathrm{mg} \mathrm{GAE} / \mathrm{g}_{\text {cake }}$ was within the range of the value obtained 
627

628

629

630

631

632

633

634

635

636

637

638

639

640

641

642

643

644

645

646

647

648

649

650

651

after defatting $\left(9.7 \pm 0.4 \mathrm{mg} / \mathrm{g}_{\text {cake }}\right)$ and therefore did not correspond to a concentration of phenolic compounds in the defatted cake proportional to the loss of oil (Ojeda-Amador et al., 2018). On the one hand, some phenols may have been co-extracted with the oil during the Soxhlet treatment, which would result in a decrease in the phenol content of the DEWAC cake. The effect of processing methods (cold pressing and hexane extraction among others in Gao et al., 2021, cold pressing and Soxhlet petroleum ether extraction in Ahmed et al., 2019) on the chemical composition and antioxidant capacity of walnut oil has been studied. In terms of phenolic content, oils extracted by hexane or petroleum ether were the richest, indicating that solvent extraction of the oil leads to coextraction of phenolic compounds and thus leaves a cake depleted in phenols compared with the untreated cake. On the other hand, a potential degradation of phenolics or a poorer access of the hydro-alcoholic solvent to phenolics after Soxhlet treatment could be also suggested. Meanwhile, ellagic acid was quantified in extracts (data as supplementary S4). It represented about $16 \%$ of the total phenolic content, a value consistent with the $15.8 \%$ content reported by Bakkalbasi, 2019 and Fukuda et al., 2003.

\section{Conclusions}

In this study, different modes and specific conditions for the extraction of phenolic compounds from a partially de-oiled walnut cake coming from an oil mill were studied. The results showed that increasing the temperature, time and solid-to-solvent ratio increased the recovery of phenolic compounds, while adding phospholipids to the solvent was not a good option. Defatting of the walnut cake with boiling hexane prior to the extraction did not concentrate the phenolic compounds in the cake and intensified ultrasonic maceration brought only slight improvements in extraction efficiency unless higher power and higher solid/solvent ratio were used. All the methods highlighted the importance of time or solid-to-solvent parameters on extraction efficiency. This work also demonstrated that the extract from walnut cake significantly increased the oxidative stability of an 
652 oil sensitive to oxidation, camelina oil. The enrichment of oils with phenolic extracts is therefore a 653 very interesting way of providing nutritional properties while extending the shelf life of the oils.

654

655 Acknowledgements.

656 Authors acknowledge Colfuturo and Minciencias from Colombia for MP. Garcia-Mendoza and FA. 657 Espinoza Pardo's scolarships.

658 


\section{References}

Adiletta, G., Magri, A., Albanese, D., Liguori, L., Sodo, M., Di Matteo, M., Petriccione, M., 2020. Overall quality and oxidative damage in packaged freshly shelled walnut kernels during cold storage. J. Food Meas. Charact. 14, 3483-3492; doi: 10.1007/s11694-020-00589-9

Ahad, T., Gull, A., Nissar, J., Masoodi, L., Rather, A., 2020. Effect of storage temperatures, packaging materials and storage periods on antioxidant activity and non-enzymatic browning of antioxidant treated walnut kernels. J. Food Sci. Technol. 57, 3556-3563; doi: $10.1007 / \mathrm{s} 13197-020-04387-5$

Ahmed, I., Juhaimi, F., Ozcan, M., Osman, M., Gassem, M., Salih, H., 2019. Effects of cold-press and soxhlet extraction systems on antioxidant activity, total phenol contents, fatty acids, and tocopherol contents of walnut kernel oils. J. Oleo Sci. 68, 167-173; doi: 10.5650/jos.ess18141

Akaike, H., 1974. A new look at the statistical model identification. IEEE Transactions on Automatic Control 19 (6) 716 - 723 ; doi: 10.1109/TAC.1974.1100705

Arranz, S., Pérez-Jiménez, J., Saura-Calixto, F., 2008. Antioxidant capacity of walnut (Juglans regia L.): contribution of oil and defatted matter. Eur. Food. Res. Technol. 227, 425-431; doi:10.1007/s00217-007-0737-2

Baümler E., Carrin, M., Carelli, A., 2016. Extraction of sunflower oil using ethanol as solvent. J. Food Eng. 178, 190-197; doi:10.1016/j.jfoodeng.2016.01.020

Bakkalbasi, E., Meral, R., Dogan, I., 2015. Bioactive compounds, physical and sensory properties of cake made with walnut press-cake. J. Food Quality 38, 422-430; doi:10.1111/jfq.12169

Bakkalbasi, E., 2019. Oxidative stability of enriched walnut oil with phenolic extracts from walnut press-cake under accelerated oxidation conditions and the effect of ultrasound treatment. J. Food Meas. Charact.13, 43-50; doi:10.1007/s11694-018-9917-y

Barba, F., Galanakis, C., Esteve, M., Frigola, A., Vorobiev, E. 2015. Potential use of pulsed electric technologies and ultrasounds to improve the recovery of high-added value compounds from blackberries. J. Food Eng. 167, 38-44; doi: 10.1016/j.jfoodeng.2015.02.001 
Bodoira, R. and Maestri, D. 2020. Phenolic compounds from nuts: extraction, chemical profiles, and bioactivity. J. Agric. Food Chem. 68, 927-942; doi:10.1021/acs.jafc.9b07160

Bursać Kovačević, D., Barba, F., Granato, D., Galanakis, C., Herceg, Z., Dragović-Uzelac, V., Putnik, P., 2018. Pressurized hot water extraction (PHWE) for the green recovery of bioactive compounds and steviol glycosides from Stevia rebaudiana Bertoni leaves. Food Chem. 254, 150-157; doi: 10.1016/j.foodchem.2018.01.192

Chemat, F., Abert Vian, M., Fabiano-Tixier, A.-S., Nutrizio, M., Režek Jambrak, A., Munekata, P., Lorenzo, J.M., Barba, F.J., Binello, A., Cravotto, G., 2020. A review of sustainable and intensified techniques for extraction of food and natural products. Green Chem., 22, 2325-2353; doi: 10.1039/C9GC03878G

Citeau, M., Albe Slabi, S., Joffre, F., Carré, P., 2018. Improved rapeseed oil extraction yield and quality via cold separation of ethanol miscella. OCL 25 (2) D207; doi:10.1051/ocl/2018012.

Dagostin, J., Carpiné, D., Corazza, M., 2015. Extraction of soybean oil using ethanol and mixtures with alkyl esters (biodiesel) as co-solvent: Kinetics and thermodynamics. Ind. Crops Prod. 74, 69-75; doi: 10.1016/j.indcrop.2015.04.054

Dai, J., Mumper, R. 2010. Plant Phenolics: Extraction, Analysis and Their Antioxidant and Anticancer Properties. Molecules 2010, 15, 7313-7352; doi:10.3390/molecules15107313.

Delgado-Adámez, J., Nieves Franco Baltasar, M., Ayuso Yuste, M.C., Martín-Vertedor, D., 2014. Oxidative stability, phenolic compounds and antioxidant potential of a virgin olive oil enriched with natural bioactive compounds. J. Oleo Sci. 63, 55-65 ; doi: 10.5650/jos.ess13114

Espinosa-Pardo, F.A., Nakajima, V.M., Macedo, G.A., Macedo, J.A., Martínez, J., 2017. Extraction of phenolic compounds from dry and fermented orange pomace using supercritical $\mathrm{CO}_{2}$ and cosolvents. Food Bioprod. Process. 101, 1-10; doi:10.1016/j.fbp.2016.10.002

Espinosa-Pardo, F.A., Savoire, R., Subra-Paternault, P., Harscoat-Schiavo, C. 2020. Oil and protein recovery from corn germ: Extraction yield, composition and protein functionality. Food Bioprod. Process. 120, 131-142; doi:10.1016/j.fbp.2020.01.002 
Fadimu, G., Ghafoor, K., Babiker, E., Al-Juhaimi, F., Abdulraheem, R., Adenekan, M., 2020. Ultrasound-assisted process for optimal recovery of phenolic compounds from watermelon (Citrullus lanatus) seed and peel. J. Food Meas. Charact. 14, 1784-1793 ; doi: 10.1007/s11694020-00426-z.

Flori, L., Macaluso, M., Taglieri, I., Sanmartin, C., Sgherri, C., De Leo, M., Ciccone, V., Donnini, S., Venturi, F., Pistelli, L., Martelli, A., Calderone, V., Testai, L., Zinnai, A., 2020. Development of fortified citrus olive oils: from their production to their nutraceutical Properties on the cardiovascular system. Nutrients 12,1557 ; doi:10.3390/nu12061557

Fregapane, G., Guisantes-Batan, E., Ojeda-Amador, R., Desamparados Salvador, M., 2020. Development of functional edible oils enriched with pistachio and walnut phenolic extracts. Food Chem. 310, 125917; doi:10.1016/j.foodchem.2019.125917

Fukuda, T., Ito, H., Yoshida, T., 2003. Antioxidative polyphenols from walnuts (Juglans regia L.). Phytochemistry 63, 795-801; doi: 10.016/S0031-9422(03)00333-9

Galanakis, C., 2018. Phenols recovered from olive mill wastewater as additives in meat products. Trends Food. Sci. Technol. 79, 98-105; 10.1016/j.tifs.2018.07.010

Galanakis, C., 2020. The food systems in the era of the coronavirus (COVID-19) pandemic crisis. Foods 9, 523; doi:10.3390/foods9040523

Gallego, R., Bueno, M., Herrero, M., 2019. Sub- and supercritical fluid extraction of bioactive compounds from plants, food-by-products, seaweeds and microalgae - An update. Trends Anal. Chem.116, 198-213; doi: 10.1016/j.trac.2019.04.030

Gao, P., Liu, R., Jin, Q., Wang, X. 2021. Effects of processing methods on the chemical composition and antioxidant capacity of walnut (Juglans regia L.) oil. LWT - Food Sci. Technol. 135, 100958; doi: 10.1016/j.lwt.2020.109958

Garcia-Mendoza, M.P., Paula, J.T., Paviani, L.C., Cabral, F.A., Martinez-Correa, H.A., 2015. Extracts from mango peel by-product obtained by supercritical $\mathrm{CO}_{2}$ and pressurized solvent processes. LWT - Food Sci. Technol. 62, 131-137; doi : 10.1016/j.lwt.2015.01.026 
Garcia-Mendoza, M. P., Espinosa-Pardo, F.A., Baseggio, A.M., Barbero, G.F., Maróstica Junior, M.R., Rostagno, M.A., Martínez, J., 2017. Extraction of phenolic compounds and anthocyanins from juçara (Euterpe edulis Mart.) residues using pressurized liquids and supercritical fluids. J. Supercrit. Fluids 119, 9-16; doi:10.1016/j.supflu.2016.08.014

Garcia-Mendoza, M.P., Espinosa-Pardo, F., Savoire, R., Harscoat-Schiavo, C., Cansell, M., SubraPaternault, P., 2021. Improvement of the oxidative stability of camelina oil by enrichment with phospholipid-quercetin formulations, Food Chem. 341,128234; doi: 10.1016/j.foodchem.2020.128234

Garcia-Mendoza, M. P., 2020. Enrichment of edible oils by incorporating phenolic antioxidants, Doctorat de l'Université de Bordeaux.

Garcia-Salas, P., Morales-Soto, A., Segura-Carretero, A., Fernandez-Gutierrez, A., 2010. Phenoliccompound-extraction systems for fruit and vegetable samples. Molecules 15, 8813-8826; doi: 10.3390/molecules15128813.

Gil, M., Tomás-Barberán, F., Hess-Pierce, B., Kader, A., 2002. Antioxidant capacities, phenolic compounds, carotenoids, and vitamin $\mathrm{C}$ contents of nectarine, peach, and plum cultivars from California. J. Agric. Food Chem. 50, 4976-4982; doi:10.1021/jf020136b

Gonçalves Rodrigues, L., Mazzutti, S., Vitali, L., Micke, G., Ferreira, S., 2019. Recovery of bioactive phenolic compounds from papaya seeds agro-industrial residue using subcritical water extraction. Biocatal. Agric. Biotechnol. 22, 101367; doi : 10.1016/j.bcab.2019.101367.

Grosso, A., Asensio, C., Nepote, V., Grosso, N., 2018. Antioxidant activity displayed by phenolic compounds cbtained from walnut oil cake used for walnut oil preservation. J. Am. Oil. Chem. Soc. 95, 1409-1419; doi: 10.1002/aocs.12145

Grosso, A., Riveros, C., Asensio, C., Grosso, N., Nepote, V., 2020. Improving walnuts' preservation by using walnut phenolic extracts as natural antioxidants through a walnut protein-based edible coating. J. Food Science 85, 3043-3051; doi: 10.1111/1750-3841.15395 
Gu, M., Chen, H.-P., Zhao, M.-M., Wang, X., Yang, B., Ren, J.-Y., Su, G.-W., 2015. Identification of antioxidant peptides released from defatted walnut (Juglans Sigillata Dode) meal proteins with pancreatin. LWT - Food Sci. Technol. 60, 213-220; doi:10.1016/j.lwt.2014.07.052

Han, H., Wang, S., Rakita, M., Wang, Y., Han, Q., Xu, Q., 2018. Effect of ultrasound-assisted extraction of phenolic compounds on the characteristics of walnut shells. Food Nutr. Sci. 9, 1034-1045; doi:10.4236/fns.2018.98076

Ho, K-H., Roy, A., Foote, S., Vo, P-H., Lall, N., Lin, C-H., 2020. Profiling anticancer and antioxidant activities of phenolic compounds present in black walnuts (Juglans nigra) using a highthroughput screening approach. Molecules, 25, 4516; doi: 10.3390/molecules25194516

Jahanban-Esfahlan, A., Ostadrahimi, A., Tabibiazar, M., Amarowicz, R., 2019. A comparative review on the extraction, antioxidant content and antioxidant potential of different parts of walnut (Juglans regia L.) fruit and tree. Molecules 24, 2133; doi:10.3390/molecules24112133.

Jacobsen, C., Let, M., Nielsen, N., Meyer, A., 2008. Antioxidant strategies for preventing oxidative flavour deterioration of foods enriched with n-3 polyunsaturated lipids: a comparative evaluation. Trends Food Sci. Technol. 19, 76-93; doi: 10.1016/j.tifs.2007.08.001

Kalogianni, A., Lazou, T., Bossis, I., Gelasakis, A., 2020. Natural phenolic compounds for the control of oxidation, bacterial spoilage, and foodborne pathogens in meat. Foods 9, 794; doi:10.3390/foods9060794

Kamali, H., Ahmadzadeh Sani, T., Mohammadi, A., Alesheikh, P., Khodaverdi, E., Hadizadeh, F. 2018. A comparison between pressurized hot water and pressurized liquid extraction for optimizing phenolic and antioxidants capacity of the wooden layer between of walnut seed. J. Supercrit. Fluids 133, 535-541; doi: 10.1016/j.supflu.2017.10.017

Kubatova, A., Jansen, B., Vaudoisot, J.-F., Hawthorne, S., 2002. Thermodynamic and kinetic models for the extraction of essential oil from savory and polycyclic aromatic hydrocarbons from soil with hot (subcritical) water and supercritical $\mathrm{CO}_{2}$. J. Chromatogr. A 975, 175-188; doi: 10.1016/S0021-9673(02)01329-8 
Kumar, K., Yadav, A., Kumar, V., Vyas, P., Dhaliwal, H., 2017. Food waste: a potential bioresource for extraction of nutraceuticals and bioactive compounds. Bioresour. Bioprocess 4, 18; doi: 10.1186/s40643-017-0148-6

Kwiatkowski, J., Cheryan, M., 2002. Extraction of Oil from Ground Corn Using Ethanol. J. Am. Oil Chem. Soc. 79, 825-830; doi: 10.1007/s11746-002-0565-8

Labuckas, D., Maestri, D., Perello, M., Martınez, M., Lamarque, L. 2008. Phenolics from walnut (Juglans regia L.) kernels: antioxidant activity and interactions with proteins. Food Chem. 107, 607-612; doi: 10.1016/j.foodchem.2007.08.05.

Li, Y., Fabiano-Tixier A.-S., Ruiz, K., Rossignol Castera, A., Bauduin, P., Diat, O., Chemat, F., 2015. Comprehension of direct extraction of hydrophilic antioxidants using vegetable oils by polar paradox theory and small angle X-ray scattering analysis. Food Chem. 173, 873-880; doi: 10.1016/j.foodchem.2014.10.0611

Li, W., Zhao, T., Zhang, J., Xu, J., Sun-Waterhouse, D., Zhao, M., \& Su, G., 2017. Effect of walnut protein hydrolysate on scopolamine-induced learning and memory deficits in mice. J. Food Sci. Technol. 54, 3102-3110; doi: 10.1007/s13197-017-2746-x

Liu, M.; Du, M.; Zhang, Y.C.; Xu,W.L.; Wang, C.; Wang, K.J.; Zhang, L.W., 2013. Purification and identification of an ACE inhibitory peptide from walnut protein. Agric. Food Chem. 61, 40974100; doi: 10.1021/jf4001378

Luo, Y., Wu, W., Chen, D., Lin, Y., Ma, Y., Chen, C., Zhao, S., 2017. Optimization of simultaneous microwave/ultrasonic-assisted extraction of phenolic compounds from walnut flour using response surface methodology. Pharmaceutical Biology, 55:1, 1999-2004; doi: $10.1080 / 13880209.2017 .1347189$

Martinez, M., Labuckas, D., Lamarque, A., Maestri D., 2010. Walnut (Juglans regia L.): genetic resources, chemistry, by-products. J. Sci. Food Agric. 90, 1959-1967; doi: 10.1002/jsfa.4059 
Martínez, J., de Aguiar, A., Machado, A., Barrales, F. Viganó, J., dos Santos, P., 2021. Process Integration and Intensification. Comprehensive Foodomics, 786-807; doi: 10.1016/B978-0-08100596-5.22819-9

Massias, A., Boisard, S., Baccaunaud, M., Leal Calderon, F., Subra-Paternault, P., 2015. Recovery of phenolics from apple peels using $\mathrm{CO}_{2}+$ ethanol extraction: kinetics and antioxidant activity of extracts. J. Supercrit. Fluids 98, 172-182; doi: 10.1016/j.supflu.2014.12.007

Minhua, Z., He, D., Zhongfeng, G., 2018. Computational study of flow and heat transfer infixed beds with cylindrical particles for low tube to particle diameter ratios. Chem. Eng. Res. Des. 132, 149-161; doi: 10.1016/j.cherd.2018.01.006

Moghadam, M., Salami, M., Mohammadian, M., Delphi, L., Sepehri, H., Emam-Djomeh, Z., Moosavi-Movahedi, A., 2020. Walnut protein-curcumin complexes: fabrication, structural characterization, antioxidant properties, and in vitro anticancer activity. J. Food Meas. Charact. 14, 876-885; doi: 10.1007/s11694-019-00336-9

Mojzer E., Hrncic, M., Škerget, M., Knez, Z., Bren, U., 2016. Polyphenols: extraction methods, antioxidative action, bioavailability and anticarcinogenic effects. Molecules 21, 901. doi:10.3390/molecules21070901

Mosca, F., Hidalgo, G-I., Villasante, J., Almajano, M-P., 2018. Continuous or batch solid-liquid extraction of antioxidant compounds from seeds of Sterculia apetala plant and kinetic release study. Molecules 23, 1759; doi: 10.3390/molecules23071759.

Navarro, S., Capellini, M., Aracava, K., Rodrigues C., 2016. Corn germ-bran oils extracted with alcoholic solvents: Extraction yield, oil composition and evaluation of protein solubility of defatted meal. Food Bioprod. Process. 100, 185-194; doi: 10.1016/j.fbp.2016.06.009.

Odabas, H., Koca, I., 2016. Application of response surface methodology for optimizing the recovery of phenolic compounds from hazelnut skin using different extraction methods. Ind. Crops Prod. 91, 114-124; doi: 10.1016/j.indcrop.2016.05.033 
Ojeda-Amador, R., Desamparados, M., Gomez-Alonso, S., Fregapane, G., 2018. Characterization of virgin walnut oils and their residual cakes produced from different varieties. Food Res. Int. 108, 396-404; doi: 10.1016/j.foodres.2018.03.066

Özcan,M., 2009. Some proximate characteristics of fruit and oil of walnut (Juglans regia L.) growing in Turkey. Iran. J. Chem. Chem. Eng. 28 (1), 57-62.

Piluzza, G., Bullitta, S., 2011. Correlations between phenolic content and antioxidant properties in twenty-four plant species of traditional ethnoveterinary use in the Mediterranean area. Pharm. Biol. 49, 240-247; doi: 10.3109/13880209.2010.501083

Pingret D., Fabiano-Tixier, A-S., Le Bourvellec, C., Renard, C., Chemat, F., 2012. Lab and pilotscale ultrasound-assisted water extraction of polyphenols from apple pomace. J. Food Eng. 111, 73-81; doi: 10.1016/j.jfoodeng.2012.01.026.

Pradal, D., Vauchel, P., Decossin, S., Dhulster, P., Dilmitrov, K., 2016. Kinetics of ultrasoundassisted extraction of antioxidant polyphenols from food by-products: Extraction and energy consumption optimization. Ultrason. Sonochem. 32, 137-146; $\quad$ doi: 10.1016/j.ultsonch.2016.03.001

Reboredo-Rodríguez, P., Figueiredo-González, M., González-Barreiro, C., Simal-Gándara, J., Desamparados Salvador, M., Cancho-Grande, B., Fregapane, G. 2017. State of the art on functional virgin olive oils enriched with bioactive compounds and their properties. Int. J. Mol. Sci. 18, 668; doi: 10.3390/ijms18030668

Romeo, R., De Bruno, A., Imeneo, V., Piscopo, A., Poiana, M., 2020. Impact of stability of enriched oil with phenolic extract from olive mill wastewaters. Foods 9, 856; doi: 10.3390/foods9070856

Rosa, R., Tassi, L., Orteca, G., Saladini, M., Villa, C., Veronesi, P., Leonelli, C., Ferrari, E., 2017. Process intensification by experimental design application to microwave-ssiasted extraction of phenolic compounds from Juglans regia L. Food Anal. Methods 10, 575-586; doi: 10.1007/s12161-016-0624-1. 
Sampaio Neto, O., Batista, E., Meirelles, A., 2018. The employment of ethanol as solvent to extract Brazil nut oil. J. Clean. Prod. 180, 866-875; doi: 10.1016/j.jclepro.2018.01.149

Santos, J., Alvarez-Ortí, M., Sena-Moreno, E., Rabadán, A., Pardo, J., Oliveira, MB., 2018. Effect of roasting conditions on the composition and antioxidant properties of defatted walnut flour. J Sci. Food Agric. 98, 1813-1820; doi: 10.1002/jsfa.8657.

Sawada, M., Venâncio, L., Toda, T., Rodrigues, C., 2014. Effects of different alcoholic extraction conditions on soybean oil yield, fatty acid composition and protein solubility of defatted meal. Food Res. Int. 62, 662-670; doi: 10.1016/j.foodres.2014.04.039

Seabra, I., Braga, M., Oliveira, R., de Sousa, H., 2019. Two-step high pressure solvent extraction of walnut (Juglans regia L.) husks: $\mathrm{scCO}_{2}+\mathrm{CO}_{2} /$ ethanol/ $\mathrm{H}_{2} \mathrm{O}$. J. $\mathrm{CO}_{2}$ Utilization 34, 375-384; doi: $10.1016 /$ j.jcou.2019.07.028

Suarez, M., Romero, M-P., Ramo, T., Motilva, M., 2011. Stability of a phenol-enriched olive oil during storage. Eur. J. Lipid Sci. Technol. 113, 894-903; doi: 10.1002/ejlt.201000432.

Subra, P. Castellani, S., Jestin, P., Aoufi, A., 1998. Extraction of $\beta$-carotene with supercritical fluids. Experiments and modelling. J. Supercrit. Fluids, 12, 261-269; doi: 10.1016/S08968446(98)00085-0

Tabaraki, R. and Rastgoo S., 2014. Comparison between conventional and ultrasound-assisted extractions of natural antioxidants from walnut green husk. Korean J. Chem. Eng. 31, 676-683; doi: $10.1007 / \mathrm{s} 11814-013-0279-1$

Vanhanen, L., Savage, G., 2006. The use of peroxide value as a measure of quality for walnut flour stored at five different temperatures using three different types of packaging. Food Chem. 99, 64-69; doi: 10.1016/j.foodchem.2005.07.020

Zhang, M., Dong, H., Geng Z., 2018. Computational study of flow and heat transfer infixed beds with cylindrical particles for low tube to particle diameter ratios. Chem. Eng. Res. Des. 132, 149161; doi: 10.1016/j.cherd.2018.01.006 
887 Zheng, Y., Wu, S., Wang, R., Wu, Y., Zhang, W., Han, Y., Tang, F., Shen, D., Liu, Y., 2020. Analysis 888 and correlationship of chemical components of various walnut (Juglans regia L.) cultivars. J. 889 Food Meas. Charact. 14, 3605-3614; doi: 10.1007/s11694-020-00603-0

890

891

892 
Table 1.

894 Coded and natural values of independent factors $(Z)$ of the fractional factorial design with the results 895 of response variables TPC and DPPH for extractions from WAC carried out by maceration.

896

\begin{tabular}{ccccccc}
\cline { 2 - 6 } & $\begin{array}{c}\text { Time }(\mathrm{min}) \\
\left(\mathrm{Z}_{1}\right)\end{array}$ & $\begin{array}{c}\text { Temperature } \\
\left({ }^{\circ} \mathrm{C}\right)\left(\mathrm{Z}_{2}\right)\end{array}$ & $\begin{array}{c}\text { Solid-solvent } \\
\text { ratio }(\mathrm{m} / \mathrm{v}) \\
\left(\mathrm{Z}_{3}\right)\end{array}$ & $\begin{array}{c}\text { Phospholipid } \\
\text { concentration } \\
(\%)\left(\mathrm{Z}_{4}\right)\end{array}$ & $\begin{array}{c}\mathrm{TPC} \\
\mathrm{mg} \\
\mathrm{GAE} / \mathrm{g}_{\text {cake }}\end{array}$ & $\begin{array}{c}\text { DPPH } \\
\mu \mathrm{mol} \\
\text { Trolox } / \mathrm{g}_{\text {cake }}\end{array}$ \\
\hline 1 & $37.5(0)$ & $44(0)$ & $1 / 19(0)$ & $0.75(0)$ & 8.23 & 68.93 \\
2 & $15(-1)$ & $28(-1)$ & $1 / 13(-1)$ & $0(-1)$ & 10.27 & 90.53 \\
3 & $60(+1)$ & $28(-1)$ & $1 / 13(-1)$ & $1.5(+1)$ & 2.54 & 42.72 \\
4 & $15(-1)$ & $28(-1)$ & $1 / 25(+1)$ & $1.5(+1)$ & 2.22 & 12.14 \\
5 & $60(+1)$ & $28(-1)$ & $1 / 25(+1)$ & $0(-1)$ & 12.04 & 99.72 \\
6 & $37.5(0)$ & $44(0)$ & $1 / 19(0)$ & $0.75(0)$ & 7.85 & 70.01 \\
7 & $60(+1)$ & $60(+1)$ & $1 / 13(-1)$ & $0(-1)$ & 11.83 & 104.91 \\
8 & $60(+1)$ & $60(+1)$ & $1 / 25(+1)$ & $1.5(+1)$ & 13.40 & 91.26 \\
9 & $15(-1)$ & $60(+1)$ & $1 / 13(-1)$ & $1.5(+1)$ & 6.56 & 60.50 \\
10 & $15(-1)$ & $60(+1)$ & $1 / 25(+1)$ & $0(-1)$ & 14.78 & 136.92 \\
11 & $37.5(0)$ & $44(0)$ & $1 / 19(0)$ & $0.75(0)$ & 8.27 & 68.75 \\
\hline & & & & & & \\
\hline
\end{tabular}


900 Coded and natural values of independent factors $(\mathrm{X})$ of the central composite design with the results 901 of response variables TPC and DPPH for extractions from DEWAC carried out by UAE.

902

\begin{tabular}{|c|c|c|c|c|c|}
\hline Run & $\begin{array}{c}\text { Power }(\mathrm{W}) \\
\left(\mathrm{X}_{1}\right)\end{array}$ & $\begin{array}{c}\text { Time (min) } \\
\left(\mathrm{X}_{2}\right)\end{array}$ & $\begin{array}{c}\text { Duty cycle }(\%) \\
\left(\mathrm{X}_{3}\right)\end{array}$ & $\begin{array}{c}\mathrm{TPC} \\
\mathrm{mg} \\
\mathrm{GAE} / \mathrm{g}_{\text {cake }}\end{array}$ & $\begin{array}{c}\text { DPPH } \\
\mu \mathrm{mol} \\
\text { Trolox } / \mathrm{g}_{\text {cake }}\end{array}$ \\
\hline 1 & $180(-1)$ & $10(-1)$ & $20(-1)$ & 10.37 & 83.0 \\
\hline 2 & $220(+1)$ & $10(-1)$ & $20(-1)$ & 11.55 & 87.5 \\
\hline 3 & $180(-1)$ & $20(+1)$ & $20(-1)$ & 11.45 & 91.0 \\
\hline 4 & $220(+1)$ & $20(+1)$ & $20(-1)$ & 12.09 & 94.8 \\
\hline 5 & $180(-1)$ & $10(-1)$ & $40(+1)$ & 12.35 & 103.1 \\
\hline 6 & $220(+1)$ & $10(-1)$ & $40(+1)$ & 13.41 & 104.7 \\
\hline 7 & $180(-1)$ & $20(+1)$ & $40(+1)$ & 12.56 & 103.3 \\
\hline 8 & $220(+1)$ & $20(+1)$ & $40(+1)$ & 13.12 & 102.8 \\
\hline 9 & $166.4(-\alpha)$ & $15(0)$ & $30(0)$ & 12.39 & 102.2 \\
\hline 10 & $233.6(+\alpha)$ & $15(0)$ & $30(0)$ & 13.16 & 104.9 \\
\hline 11 & $200(0)$ & $6.6(-\alpha)$ & $30(0)$ & 11.66 & 93.5 \\
\hline 12 & $200(0)$ & $23.4(+\alpha)$ & $30(0)$ & 13.26 & 106.9 \\
\hline 13 & $200(0)$ & $15(0)$ & $13.2(-\alpha)$ & 12.03 & 104.2 \\
\hline 14 & $200(0)$ & $15(0)$ & $46.8(+\alpha)$ & 12.86 & 107.1 \\
\hline 15 & $200(0)$ & $15(0)$ & $30(0)$ & 12.05 & 97.7 \\
\hline 16 & $200(0)$ & $15(0)$ & $30(0)$ & 12.69 & 99.3 \\
\hline 17 & $200(0)$ & $15(0)$ & $30(0)$ & 12.16 & 103.2 \\
\hline 18 & $200(0)$ & $15(0)$ & $30(0)$ & 12.41 & 103.6 \\
\hline 19 & $200(0)$ & $15(0)$ & $30(0)$ & 12.20 & 105.5 \\
\hline 20 & $200(0)$ & $15(0)$ & $30(0)$ & 12.84 & 104.7 \\
\hline
\end{tabular}


903

904 
905 Table 3.

906 Kinetic parameters of extractions carried out by COL semi-continuous method from walnut press-

907 cake.

908

\begin{tabular}{|c|c|c|c|}
\hline & $\begin{array}{l}\text { Storage }-18^{\circ} \mathrm{C} \\
\text { Filler } 0.5 \mathrm{~mm}\end{array}$ & $\begin{array}{c}\text { Storage }-18^{\circ} \mathrm{C} \\
\text { Filler } 2 \mathrm{~mm}\end{array}$ & $\begin{array}{c}\text { Storage room T } \\
\text { Filler } 0.5 \mathrm{~mm}\end{array}$ \\
\hline \multicolumn{4}{|c|}{ Extraction yield ( $\left.g_{\text {extract }} / g_{W A C}\right)$} \\
\hline$Y_{\infty}$ & 0.25 & 0.25 & 0.25 \\
\hline $\mathrm{f}$ & 0.947 & 0.815 & 0.495 \\
\hline $\mathrm{k}_{1}\left(\min ^{-1}\right)$ & 0.070 & 0.071 & 0.073 \\
\hline $\mathrm{k}_{2}\left(\min ^{-1}\right)$ & 0.002 & 0.002 & 0.004 \\
\hline \multicolumn{4}{|c|}{$T P C\left(m g G A E / g_{W A C}\right)$} \\
\hline$Y_{\infty}$ & 21.8 & 21.8 & 15.5 \\
\hline f & 0.087 & 0.027 & 0.021 \\
\hline $\mathrm{k}_{1}$ & 0.023 & 0.047 & 0.030 \\
\hline $\mathrm{k}_{2}$ & 0.020 & 0.015 & 0.026 \\
\hline
\end{tabular}

909 


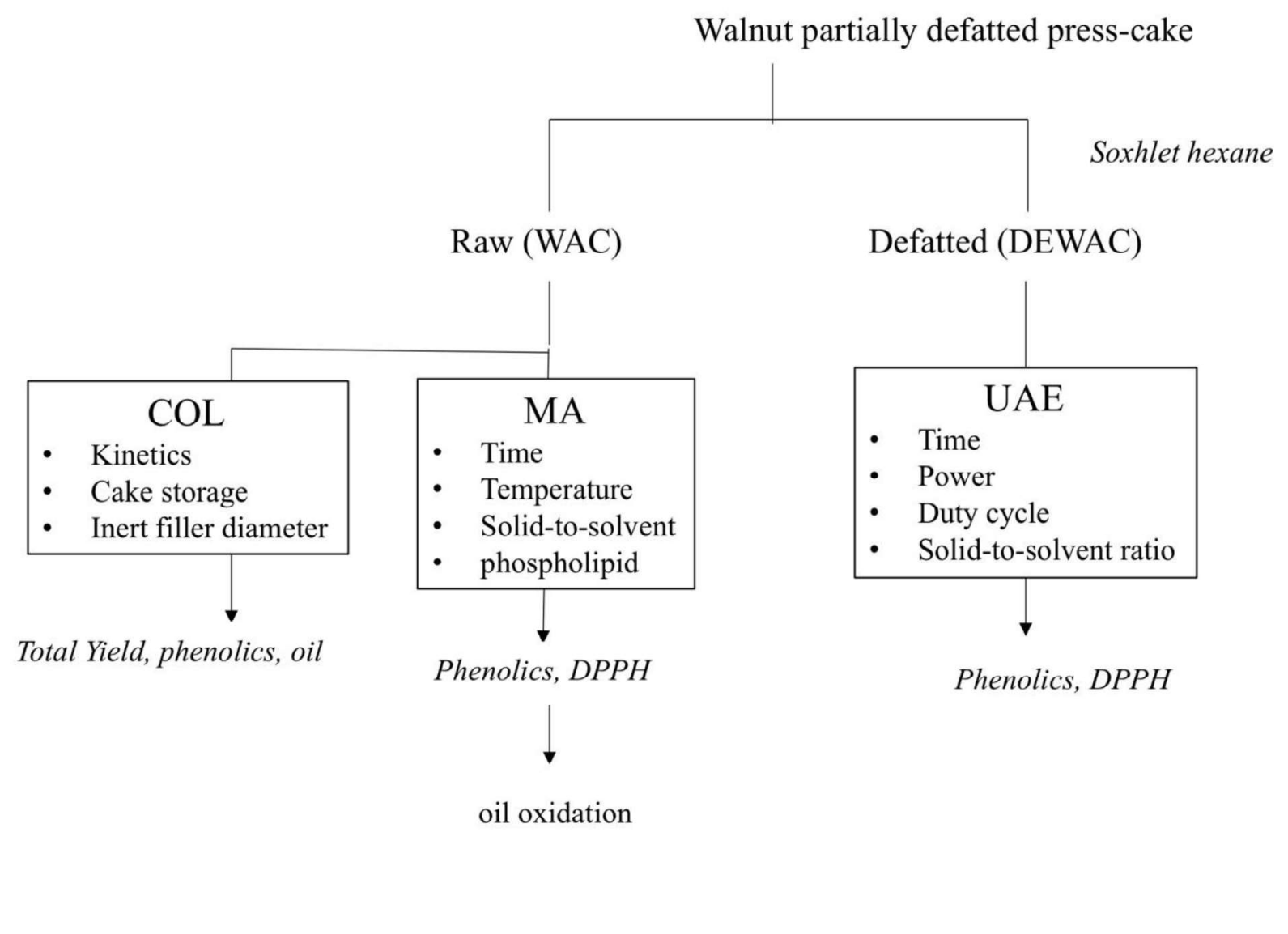

914 Fig. 1. Overview of extractions methods and variables: batch maceration (MA), maceration assisted 915 by ultrasounds (UAE), semi-continuous extraction (COL).

916

917 
a

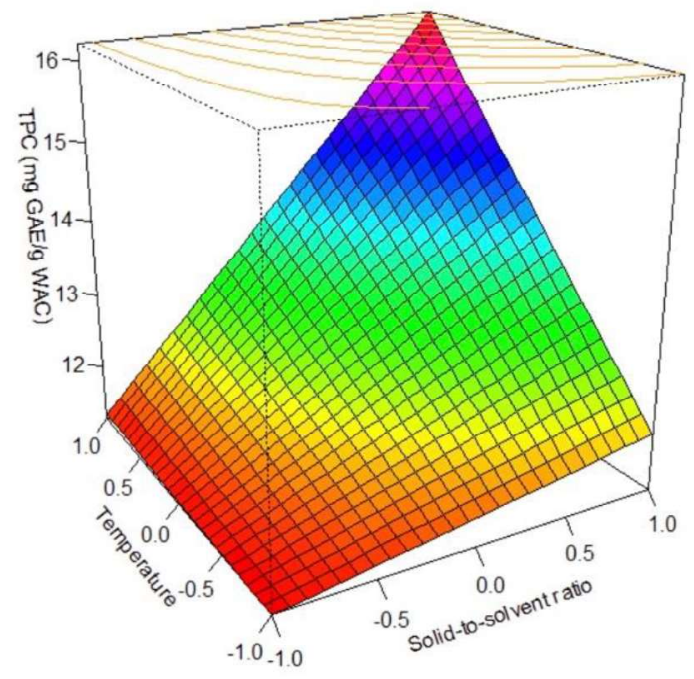

b

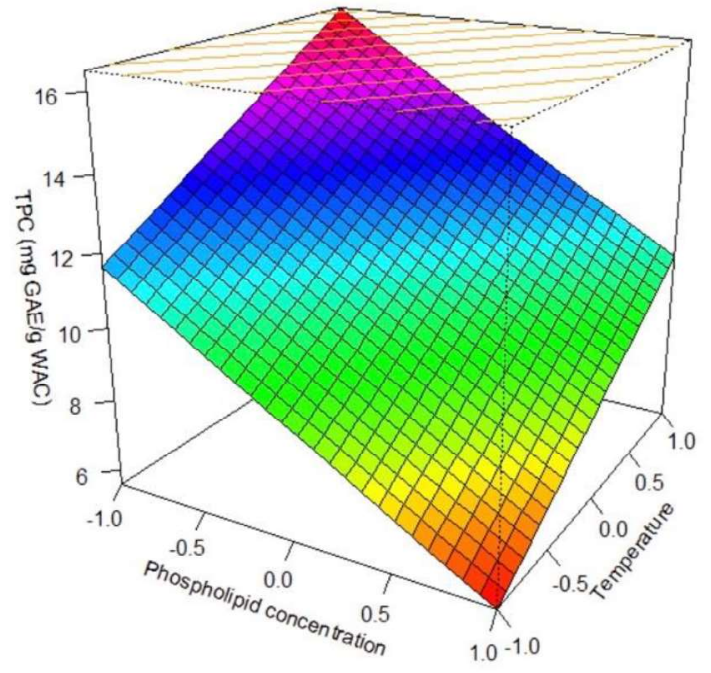

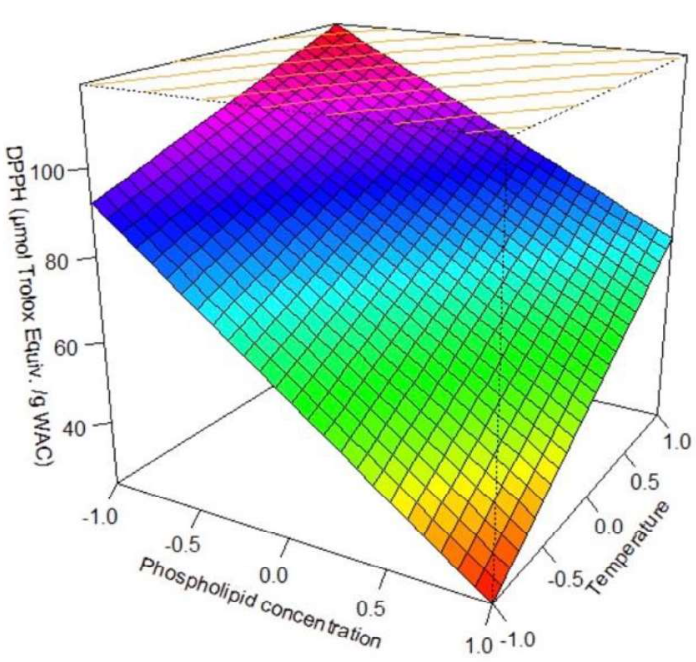

919 Fig. 2. Response surface plots for the effect of variables of maceration MA from WAC press-cake on

920 total phenolics recovery TPC (a : slice at $Z_{1}=+1$ and $Z_{4}=-1 ; b$ : slice at $Z_{1}=+1$ and $\left.Z_{3}=+1\right)$ and 921 antioxidant activity DPPH.

922

923 


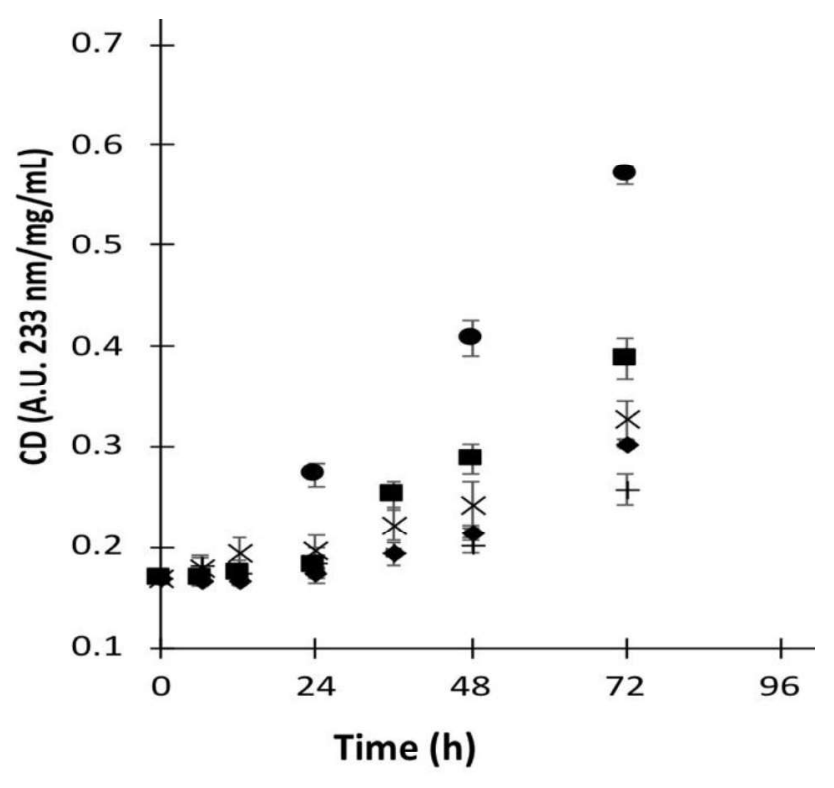

924

925 Fig. 3. Monitoring of CD formation under heating accelerated conditions of (•) pure Coil, ( $\bullet$ ) Coil $926+$ WAC extract (150 mg/kg), (x) Coil + phosphatidylcholine (20 mg/g) + WAC extract (150 mg/kg),

927 ( $)$ Coil + WAC extract (1 $500 \mathrm{mg} / \mathrm{kg})$, and (+) Coil + phosphatidylcholine $(20 \mathrm{mg} / \mathrm{g})+$ WAC extract $928 \quad(1500 \mathrm{mg} / \mathrm{kg})$.

929

930 

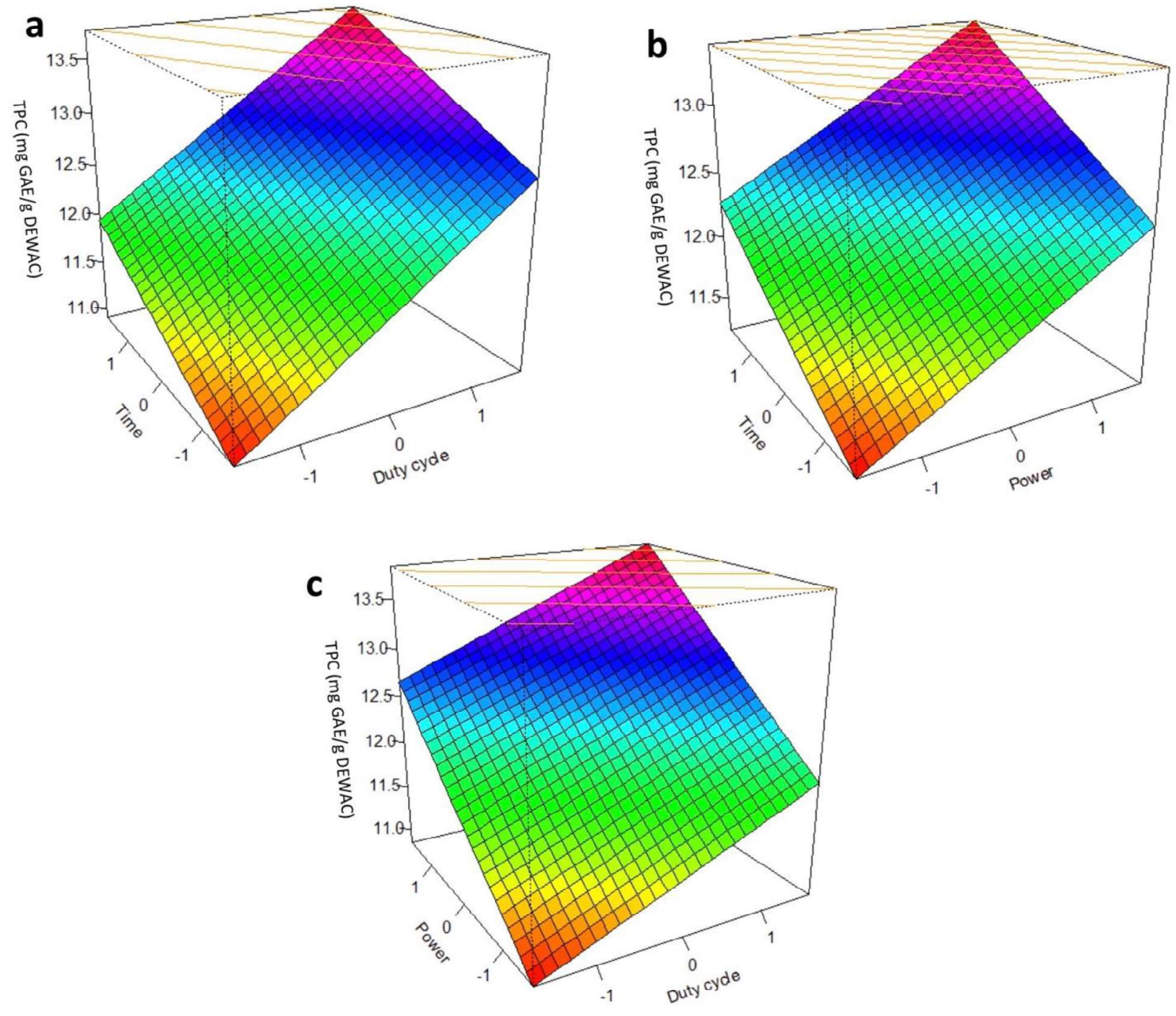

937 Fig. 4: Response surface plots for the effect of variables of UAE from DEWAC press-cake on total 938 phenolics recovery TPC (a: slice at $\mathrm{X}_{1}=0$; b: slice at $\mathrm{X}_{3}=0$; c: slice at $\mathrm{X}_{2}=0$ ). 


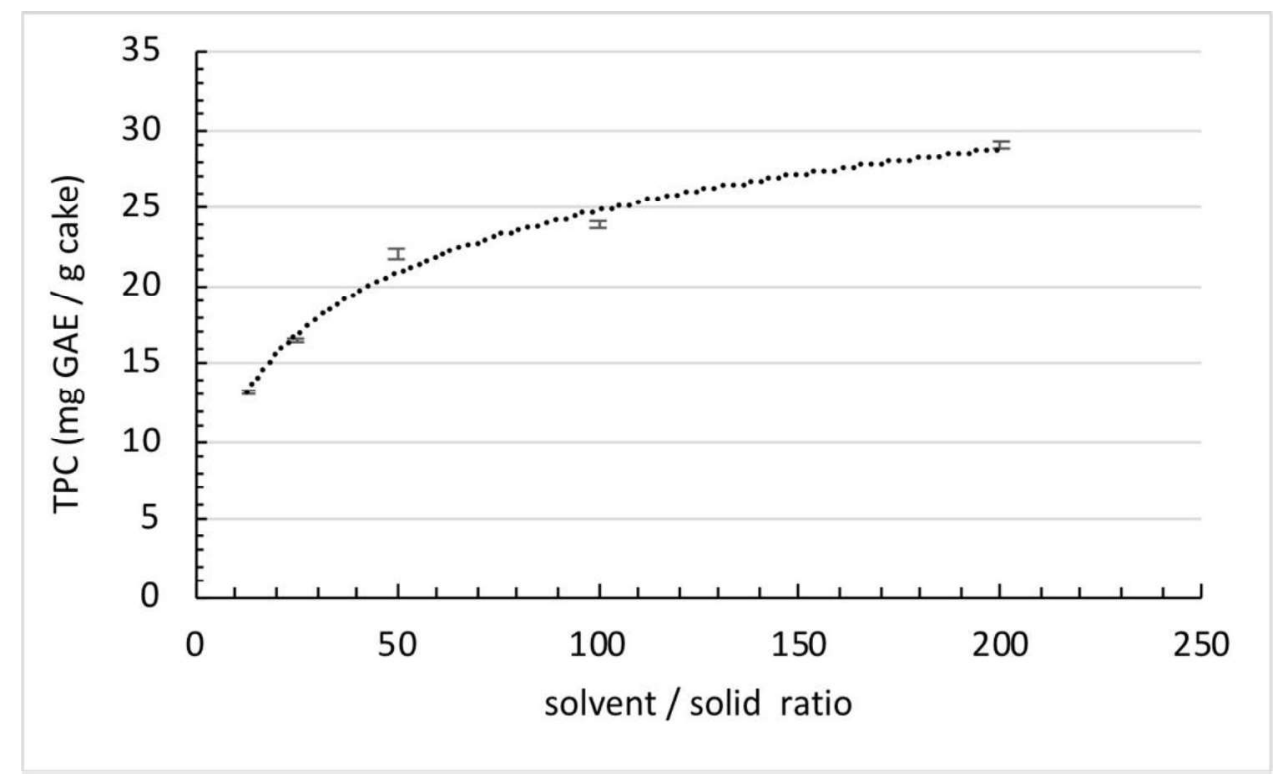

943 Fig.5. Effect of solid-solvent ratio on TPC recovery in UAE experiments.

944

945 


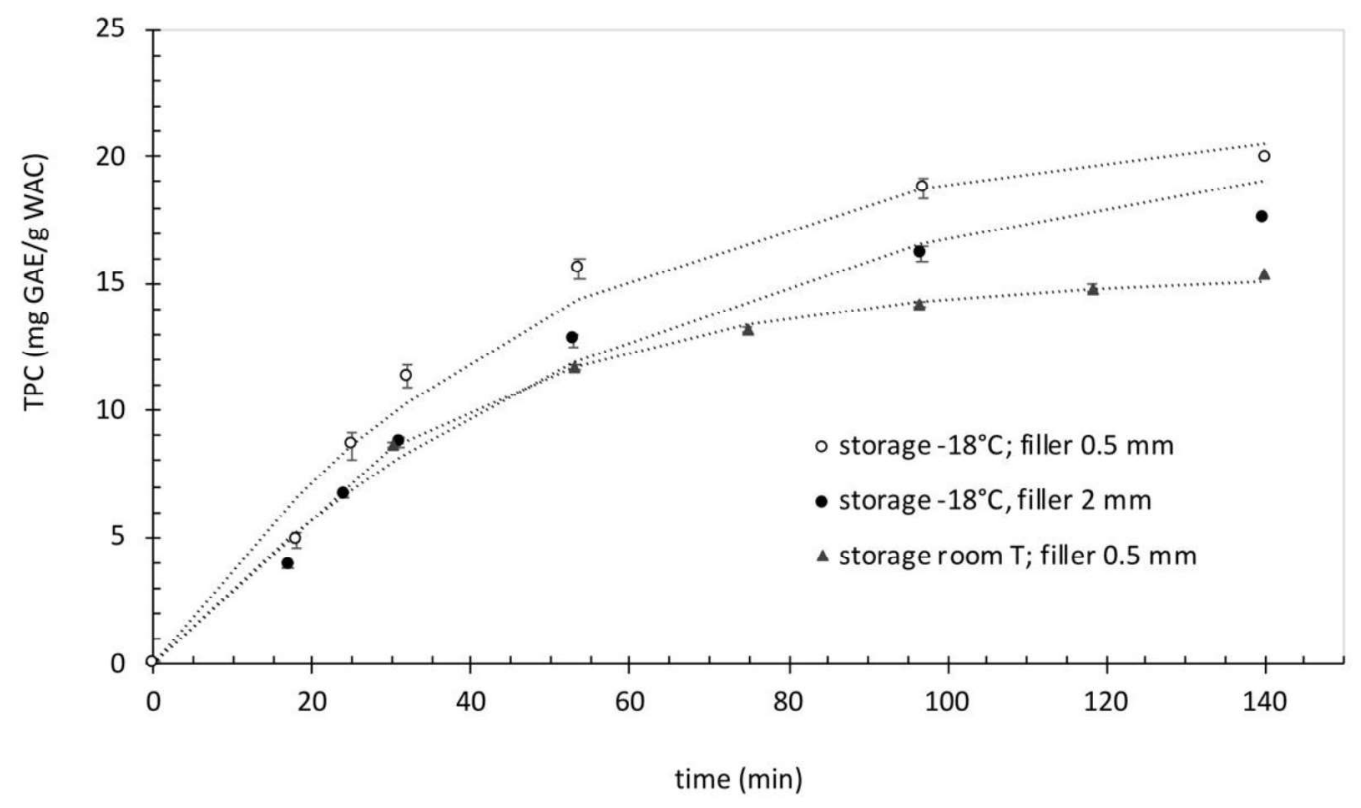

947

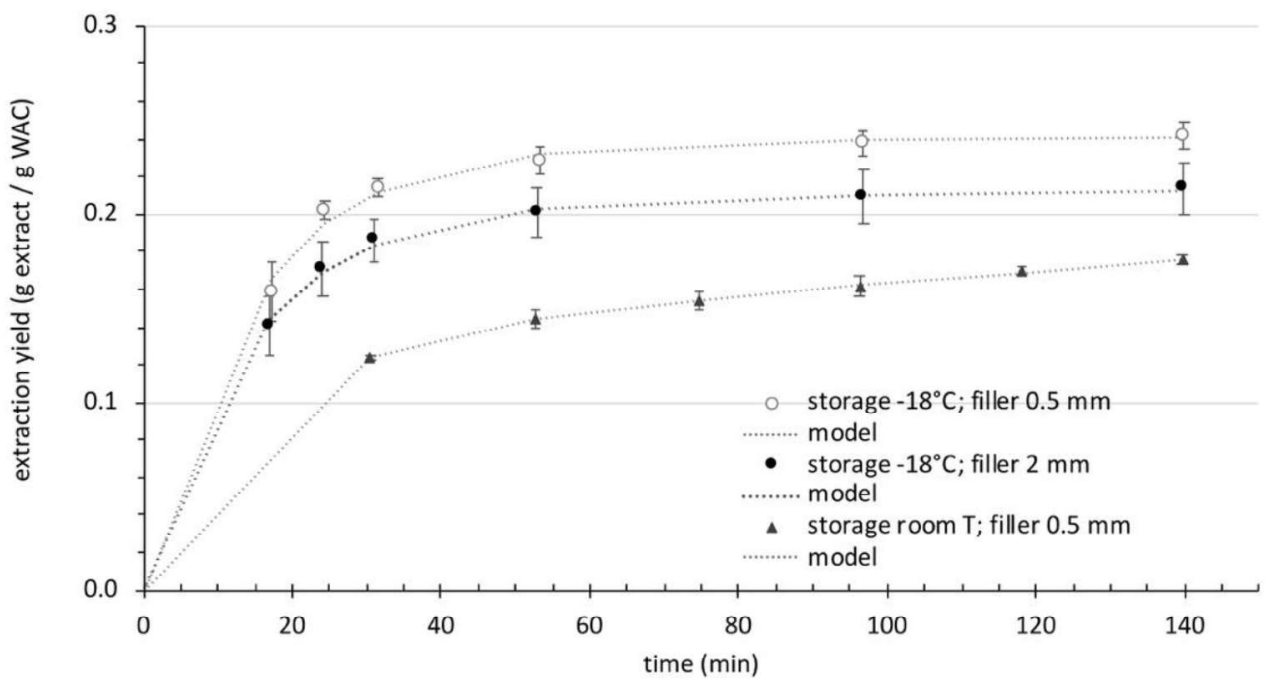

950 Fig. 6. Extraction kinetics of phenolic compounds and total extract from WAC walnut cake in COL 951 experiments. 
954

955

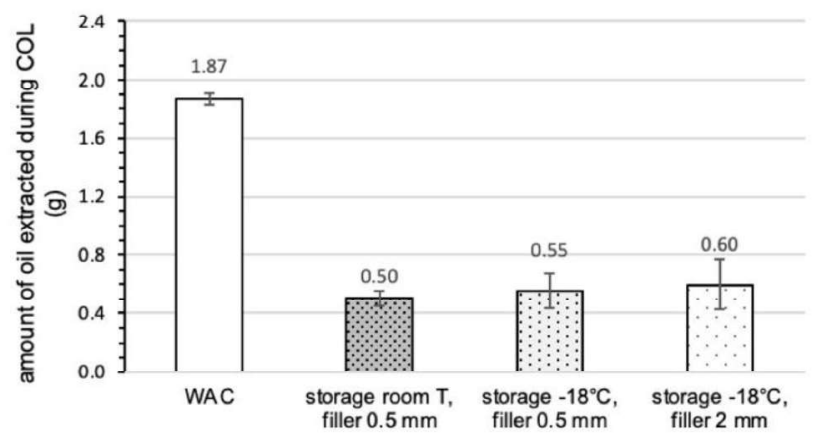

956 Fig. 7. Amount of oil extracted in COL experiments from $5 \mathrm{~g}$ of WAC, compared with the extractable 957 amount present in the untreated cake (WAC label).

958

959 
961

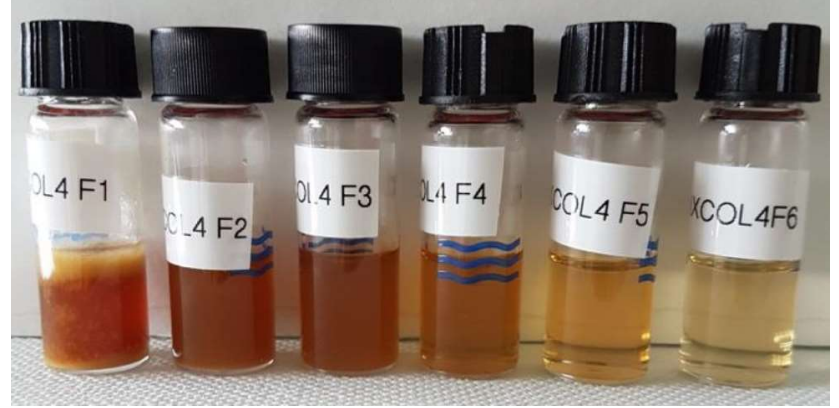

962 Fig. 8. Aliquots of fractions collected during the semi-continuous COL extraction of WAC (essay 963 'storage $-18^{\circ} \mathrm{C}$, filler $0.5 \mathrm{~mm}$ ').

964 


\begin{tabular}{ccccccc}
\cline { 2 - 6 } & $\begin{array}{c}\text { Time }(\mathrm{min}) \\
\left(\mathrm{Z}_{1}\right)\end{array}$ & $\begin{array}{c}\text { Temperature } \\
\left({ }^{\circ} \mathrm{C}\right)\left(\mathrm{Z}_{2}\right)\end{array}$ & $\begin{array}{c}\text { Solid-to- } \\
\text { solvent ratio } \\
(\mathrm{m} / \mathrm{v})\left(\mathrm{Z}_{3}\right)\end{array}$ & $\begin{array}{c}\text { Phospholipid } \\
\text { concentration } \\
(\%)\left(\mathrm{Z}_{4}\right)\end{array}$ & $\begin{array}{c}\text { TPC } \\
\text { mg GAE/g }\end{array}$ & $\begin{array}{c}\text { DPPH } \\
\mu \text { Trolox/g }\end{array}$ \\
\hline 1 & $37.5(0)$ & $44(0)$ & $1 / 19(0)$ & $0.75(0)$ & 8.23 & 68.93 \\
2 & $15(-1)$ & $28(-1)$ & $1 / 13(-1)$ & $0(-1)$ & 10.27 & 90.53 \\
3 & $60(+1)$ & $28(-1)$ & $1 / 13(-1)$ & $1.5(+1)$ & 2.54 & 42.72 \\
4 & $15(-1)$ & $28(-1)$ & $1 / 25(+1)$ & $1.5(+1)$ & 2.22 & 12.14 \\
5 & $60(+1)$ & $28(-1)$ & $1 / 25(+1)$ & $0(-1)$ & 12.04 & 99.72 \\
6 & $37.5(0)$ & $44(0)$ & $1 / 19(0)$ & $0.75(0)$ & 7.85 & 70.01 \\
7 & $60(+1)$ & $60(+1)$ & $1 / 13(-1)$ & $0(-1)$ & 11.83 & 104.91 \\
8 & $60(+1)$ & $60(+1)$ & $1 / 25(+1)$ & $1.5(+1)$ & 13.40 & 91.26 \\
9 & $15(-1)$ & $60(+1)$ & $1 / 13(-1)$ & $1.5(+1)$ & 6.56 & 60.50 \\
10 & $15(-1)$ & $60(+1)$ & $1 / 25(+1)$ & $0(-1)$ & 14.78 & 136.92 \\
11 & $37.5(0)$ & $44(0)$ & $1 / 19(0)$ & $0.75(0)$ & 8.27 & 68.75 \\
\hline
\end{tabular}




\begin{tabular}{|c|c|c|c|c|c|}
\hline Run & $\begin{array}{c}\text { Power }(\mathrm{W}) \\
\left(\mathrm{X}_{1}\right)\end{array}$ & $\begin{array}{l}\text { Time }(\min ) \\
\left(\mathrm{X}_{2}\right)\end{array}$ & $\begin{array}{l}\text { Duty cycle } \\
(\%)\left(\mathrm{X}_{3}\right)\end{array}$ & $\begin{array}{c}\text { TPC } \\
\mathrm{mg} \mathrm{GAE} / \mathrm{g}\end{array}$ & $\begin{array}{c}\text { DPPH } \\
\mu \mathrm{mol} \text { Trolox } / \mathrm{g}\end{array}$ \\
\hline 1 & $180(-1)$ & $10(-1)$ & $20(-1)$ & 10.37 & 83.0 \\
\hline 2 & $220(+1)$ & $10(-1)$ & $20(-1)$ & 11.55 & 87.5 \\
\hline 3 & $180(-1)$ & $20(+1)$ & $20(-1)$ & 11.45 & 91.0 \\
\hline 4 & $220(+1)$ & $20(+1)$ & $20(-1)$ & 12.09 & 94.8 \\
\hline 5 & $180(-1)$ & $10(-1)$ & $40(+1)$ & 12.35 & 103.1 \\
\hline 6 & $220(+1)$ & $10(-1)$ & $40(+1)$ & 13.41 & 104.7 \\
\hline 7 & $180(-1)$ & $20(+1)$ & $40(+1)$ & 12.56 & 103.3 \\
\hline 8 & $220(+1)$ & $20(+1)$ & $40(+1)$ & 13.12 & 102.8 \\
\hline 9 & $166.4(-\alpha)$ & $15(0)$ & $30(0)$ & 12.39 & 102.2 \\
\hline 10 & $233.6(+\alpha)$ & $15(0)$ & $30(0)$ & 13.16 & 104.9 \\
\hline 11 & $200(0)$ & $6.6(-\alpha)$ & $30(0)$ & 11.66 & 93.5 \\
\hline 12 & $200(0)$ & $23.4(+\alpha)$ & $30(0)$ & 13.26 & 106.9 \\
\hline 13 & $200(0)$ & $15(0)$ & $13.2(-\alpha)$ & 12.03 & 104.2 \\
\hline 14 & $200(0)$ & $15(0)$ & $46.8(+\alpha)$ & 12.86 & 107.1 \\
\hline 15 & $200(0)$ & $15(0)$ & $30(0)$ & 12.05 & 97.7 \\
\hline 16 & $200(0)$ & $15(0)$ & $30(0)$ & 12.69 & 99.3 \\
\hline 17 & $200(0)$ & $15(0)$ & $30(0)$ & 12.16 & 103.2 \\
\hline 18 & $200(0)$ & $15(0)$ & $30(0)$ & 12.41 & 103.6 \\
\hline 19 & $200(0)$ & $15(0)$ & $30(0)$ & 12.20 & 105.5 \\
\hline 20 & $200(0)$ & $15(0)$ & $30(0)$ & 12.84 & 104.7 \\
\hline
\end{tabular}




\begin{tabular}{|c|c|c|c|}
\hline & Storage $-18^{\circ} \mathrm{C}$ & Storage $-18^{\circ} \mathrm{C}$ & Storage room $\mathrm{T}$ \\
\hline & Filler $0.5 \mathrm{~mm}$ & Filler $2 \mathrm{~mm}$ & Filler $0.5 \mathrm{~mm}$ \\
\hline \multicolumn{4}{|c|}{ Extraction yield ( $\left.g_{\text {extract }} / g_{W A C}\right)$} \\
\hline$Y_{\infty}$ & 0.25 & 0.25 & 0.25 \\
\hline $\mathrm{f}$ & 0.947 & 0.815 & 0.495 \\
\hline $\mathrm{k}_{1}\left(\min ^{-1}\right)$ & 0.070 & 0.071 & 0.073 \\
\hline $\mathrm{k}_{2}\left(\min ^{-1}\right)$ & 0.002 & 0.002 & 0.004 \\
\hline \multicolumn{4}{|c|}{$T P C\left(m g G A E / g_{W A C}\right)$} \\
\hline$Y_{\infty}$ & 21.8 & 21.8 & 15.5 \\
\hline $\mathrm{f}$ & 0.087 & 0.027 & 0.021 \\
\hline $\mathrm{k}_{1}$ & 0.023 & 0.047 & 0.030 \\
\hline $\mathrm{k}_{2}$ & 0.020 & 0.015 & 0.026 \\
\hline
\end{tabular}




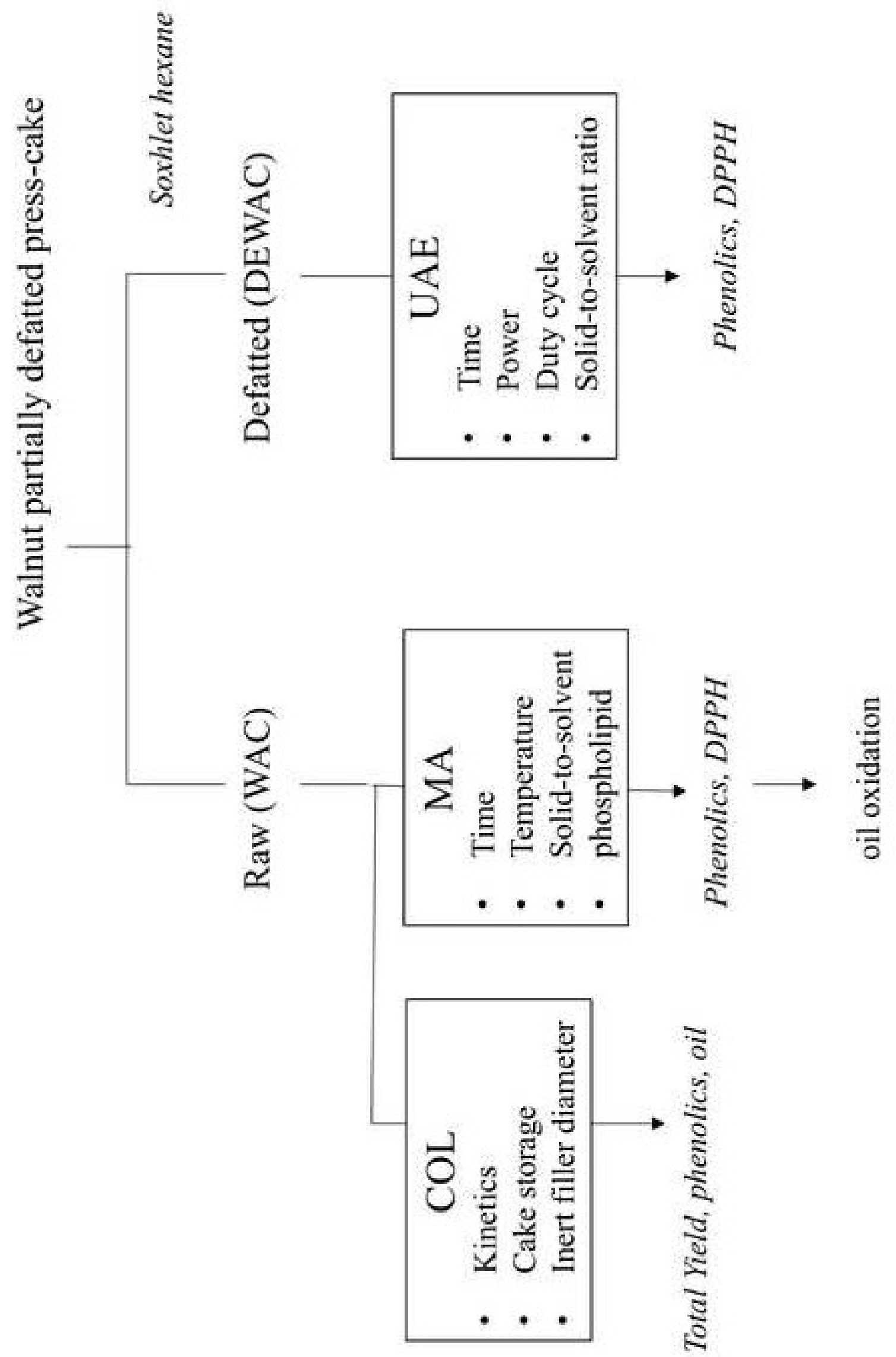



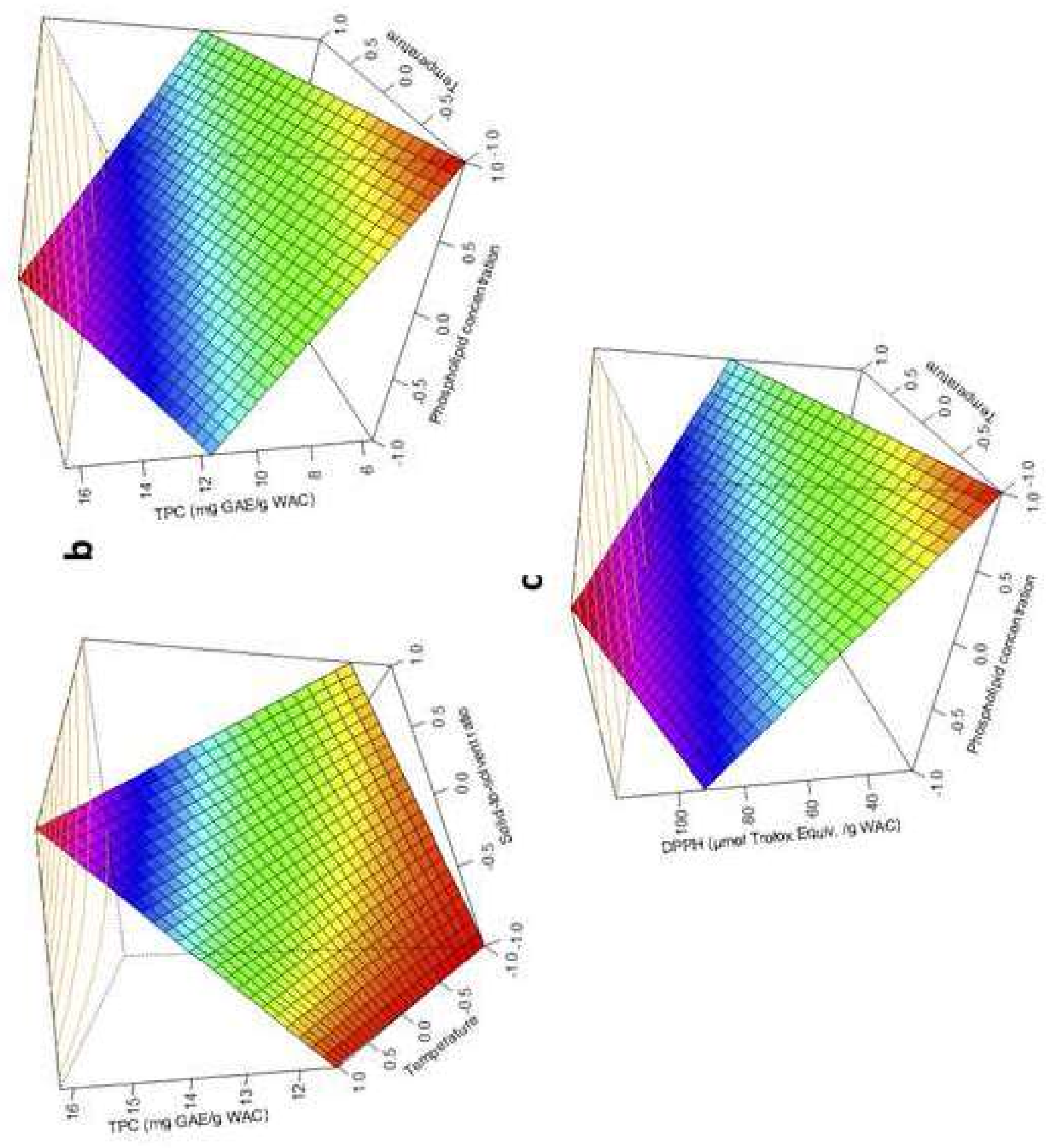

N 


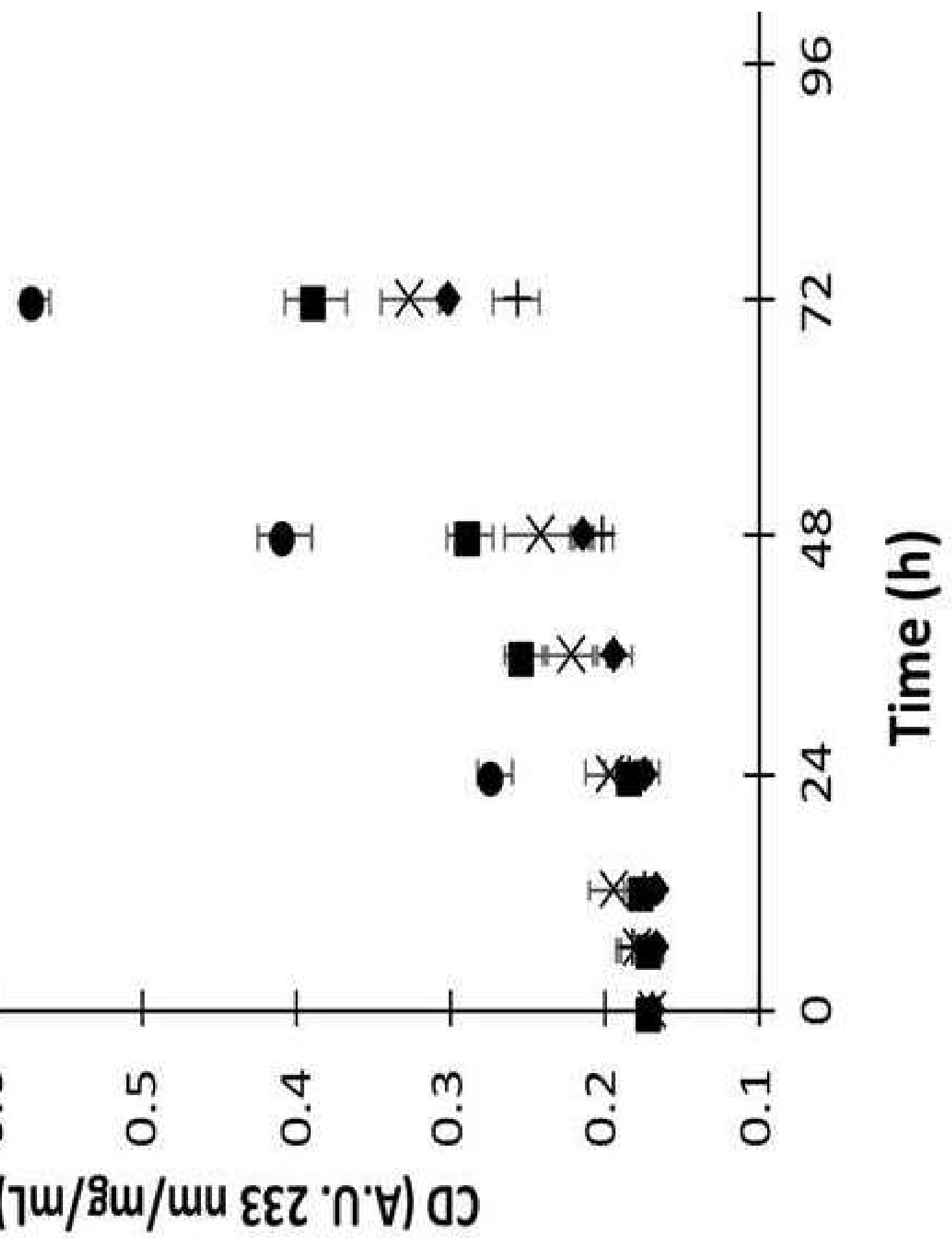

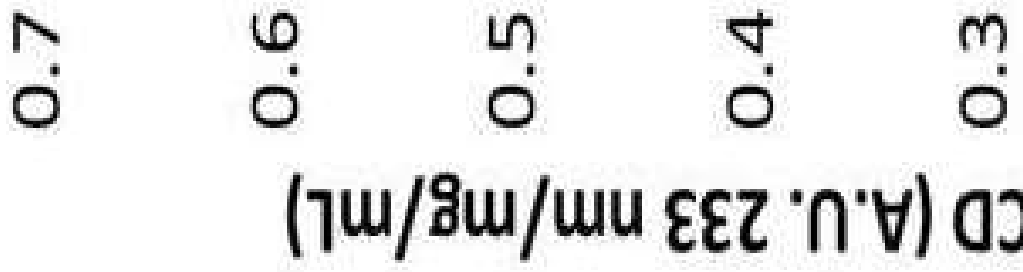



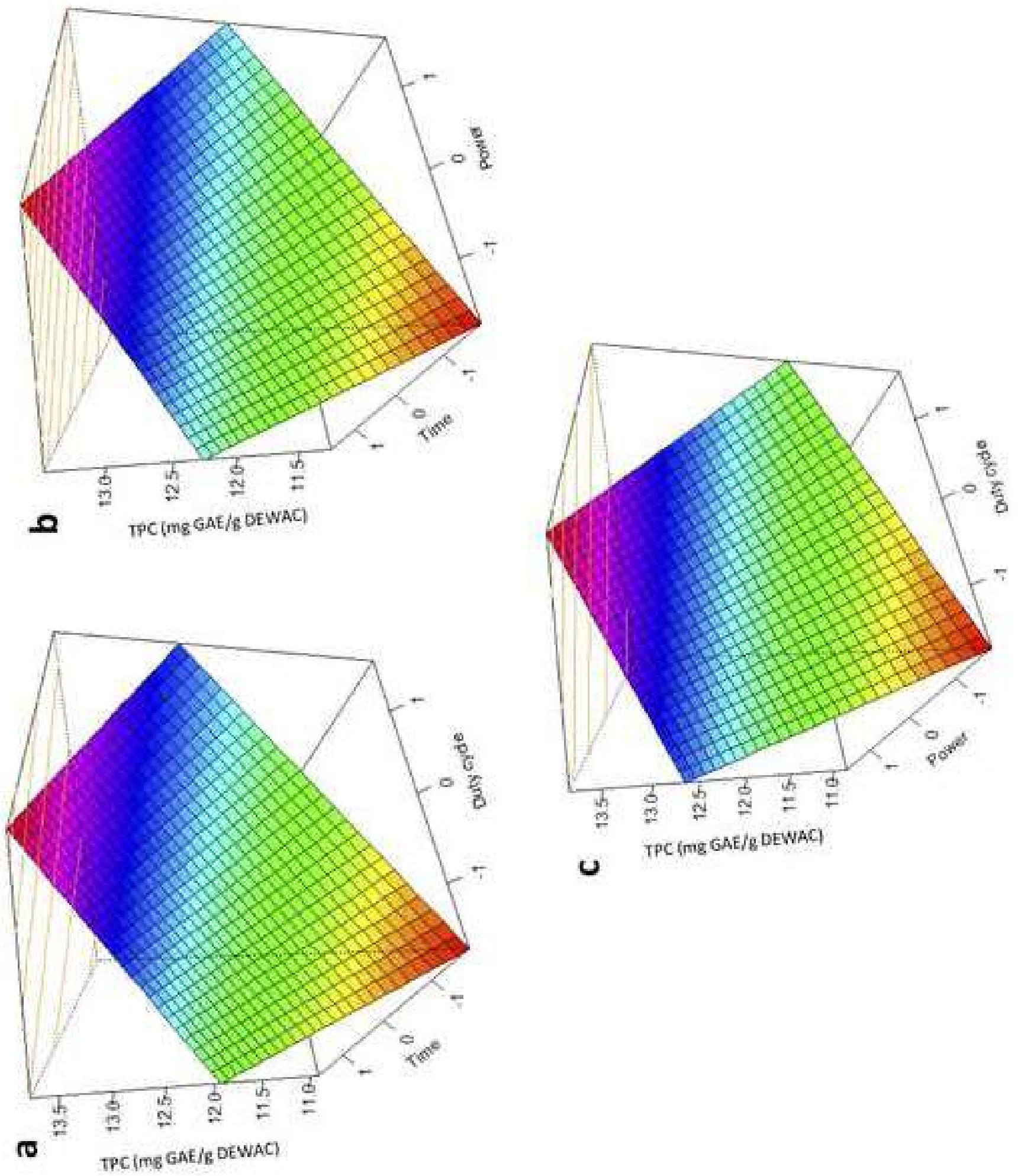


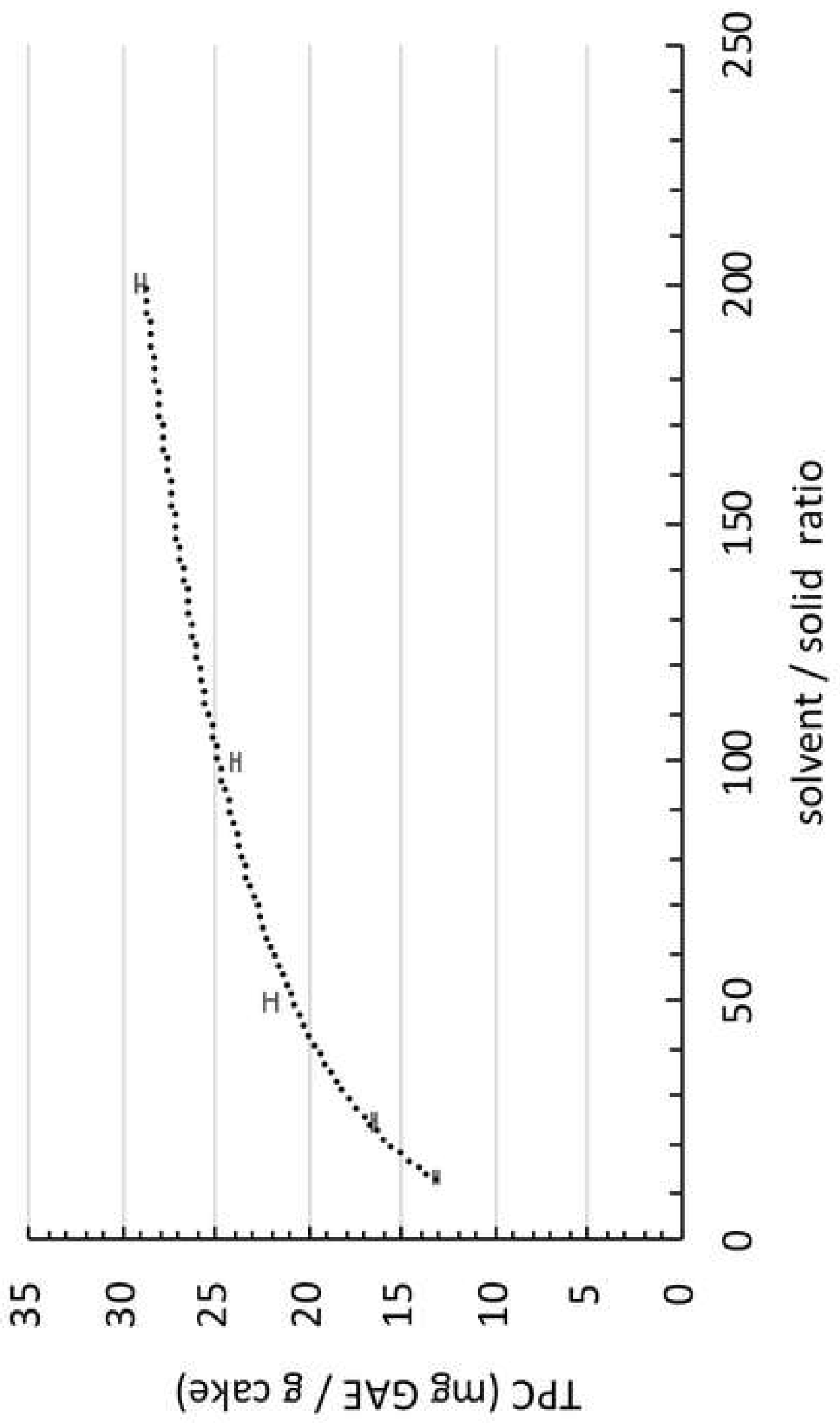

10
$\stackrel{\mathbb{1}}{5}$
$\stackrel{5}{7}$ 


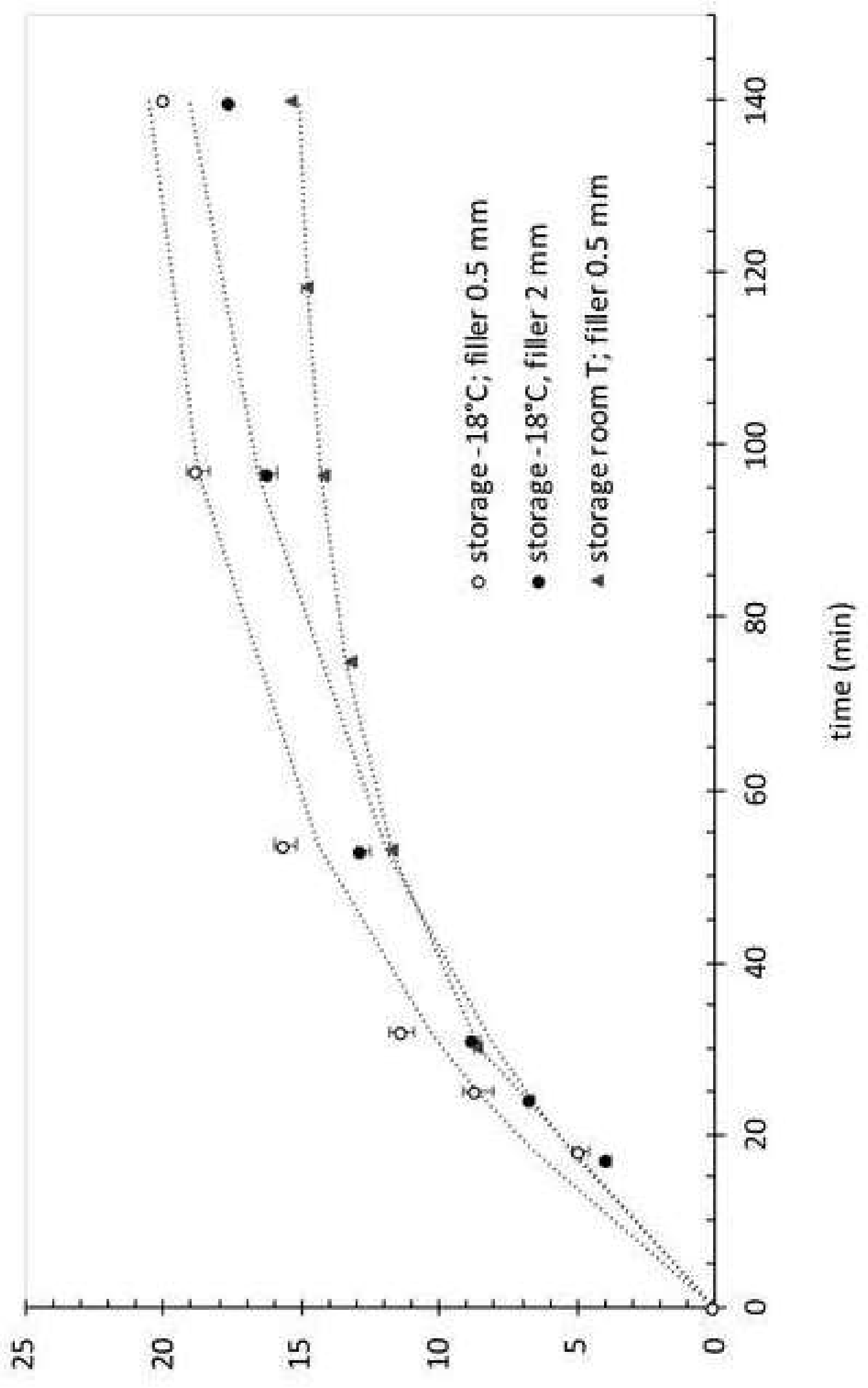

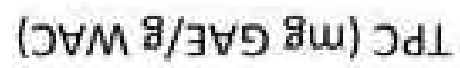




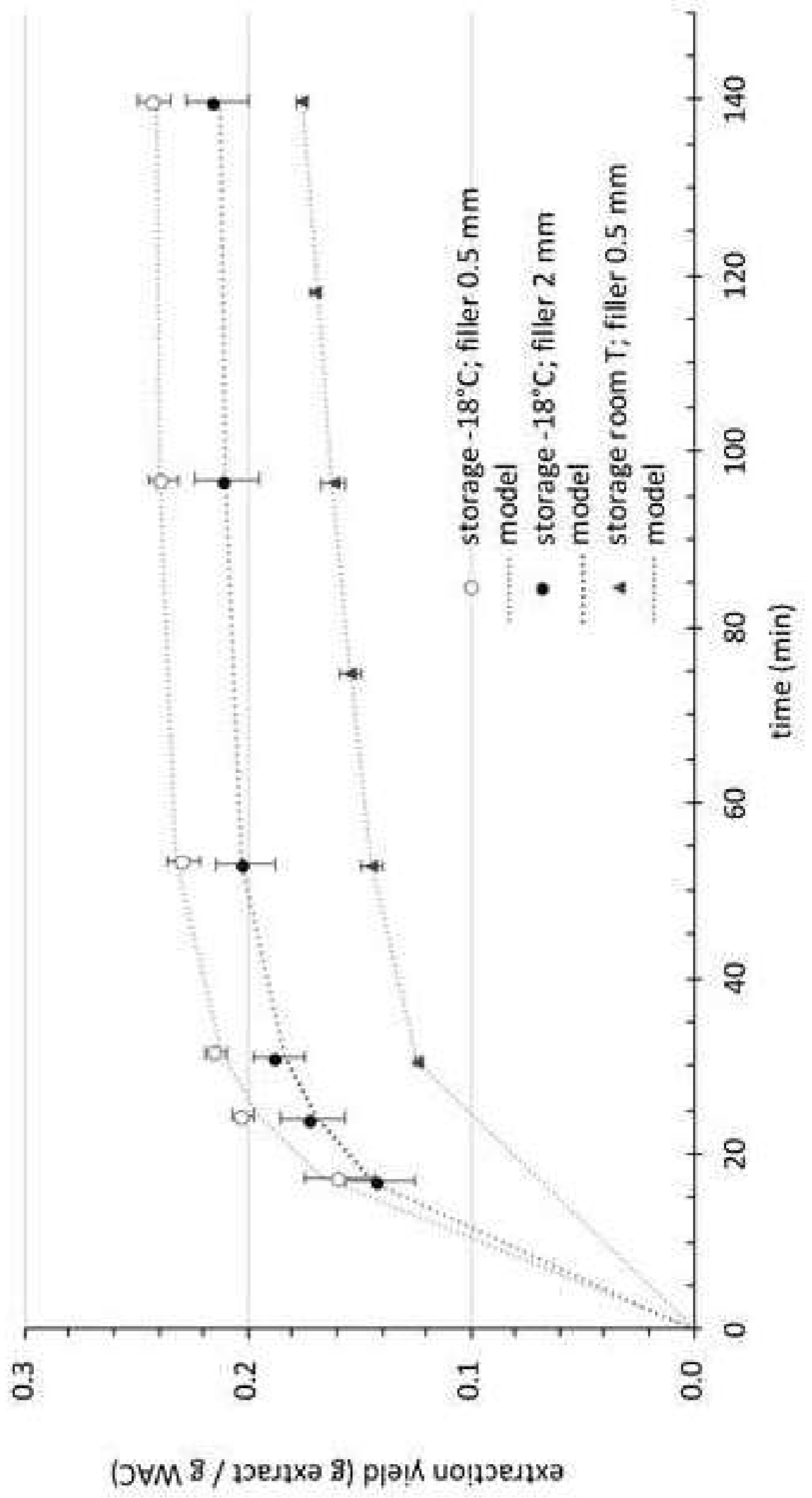

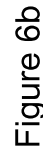




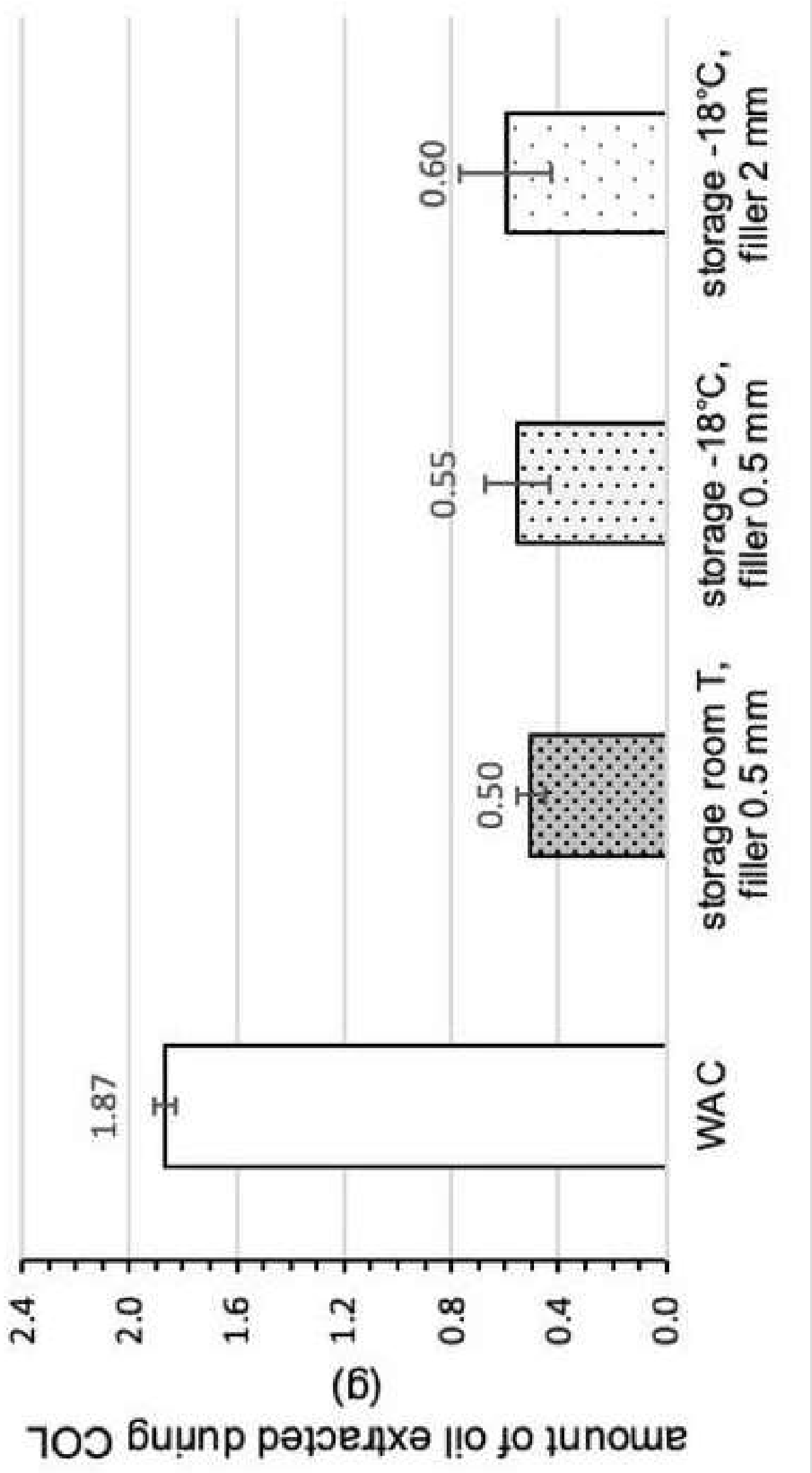




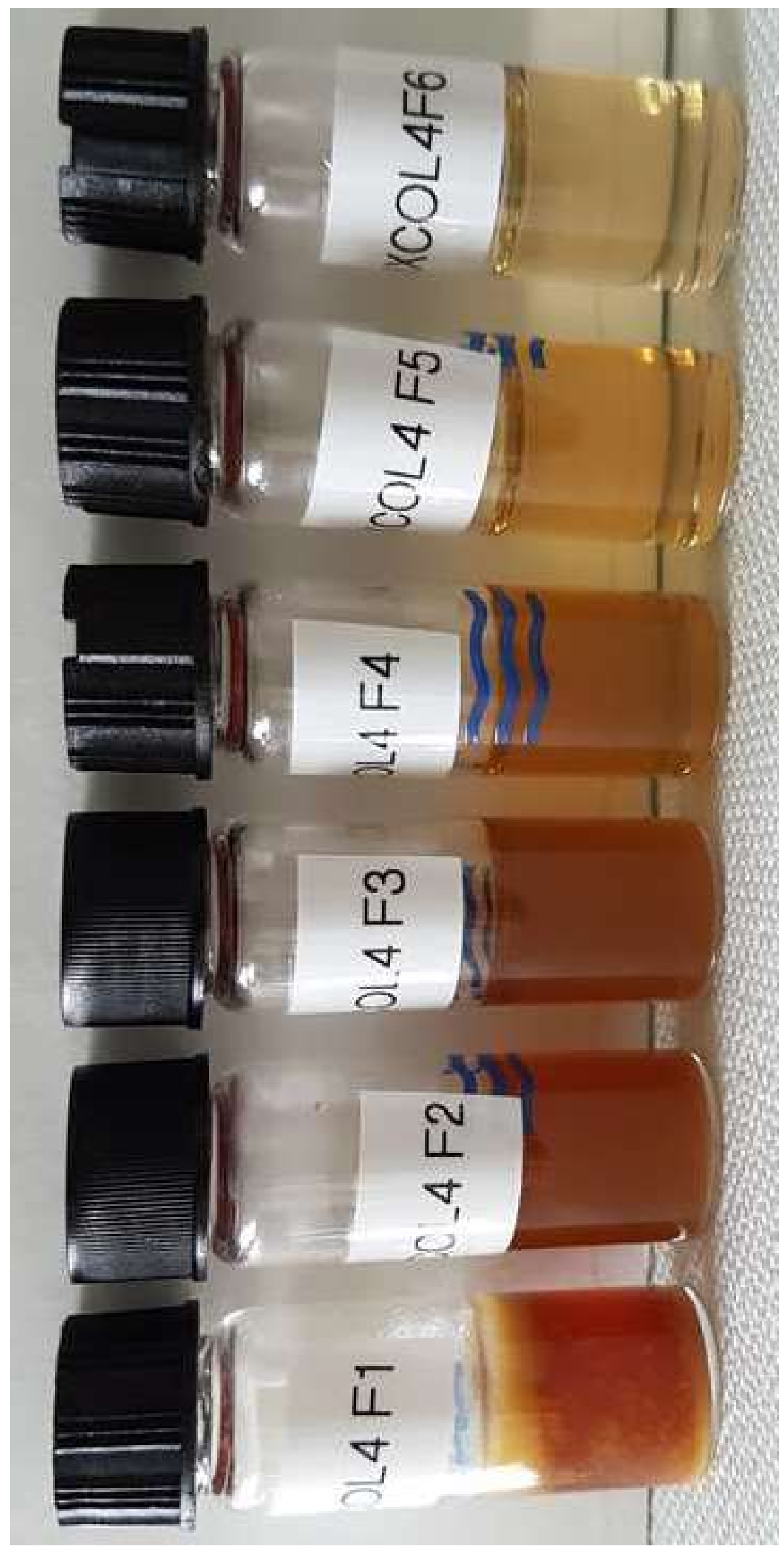

